\title{
EL PUEBLO MAPUCHE Y LAS DICTADURAS CÍVICO MILITARES EN ARGENTINA: POLÍTICAS PÚBLICAS, TRAYECTORIAS $Y$ DEMANDAS DE REPARACIÓN
}

\author{
HUGO TRINCHERO
}

CONICET/UNPAZ/UBA

IVANNA PETZ

CONICET/UBA

SEBASTIÁN VALVERDE

CONICET/UBA/UNLU

\begin{abstract}
RESUMEN: En la Argentina, los dramáticos hechos y efectos de las dictaduras cívico-militares han sido largamente abordados por vastos sectores, organizaciones sociales, el Estado y los ámbitos académicos - dado el peso que han tenido, en nuestro país, las organizaciones de derechos humanos-. Sin embargo, se plantea una situación particular con los pueblos indígenas: la suerte de estos durante los períodos de dictaduras cívico-militares es una temática escasamente tratada, invisibilizada y sobre la cual hay muchísimo (o casi todo) por hacer. Nos proponemos analizar estas dinámicas, a partir de situaciones que involucran a poblaciones y comunidades del pueblo Mapuche en Norpatagonia Argentina, específicamente en la zona del Parque Nacional Nahuel Huapi (en la región cordillerana de las provincias de Río Negro y Neuquén), en relación con diferentes desalojos que tuvieron lugar cuando las garantías constitucionales estaban suspendidas, en las décadas de 1950, 1960 y 1970. Por último, ahondaremos en el trabajo articulado de diferentes equipos universitarios con los pueblos originarios y cómo esto ha contribuido a una visibilización de los acontecimientos, como parte fundamental de la memoria y la identidad de los pueblos.
\end{abstract}

PALABRAS-CLAVE: pueblo Mapuche; dictaduras cívico-militares en la Argentina; Parque Nacional Nahuel Huapi; décadas de 1950, 1960 y 1970.

ABSTRACT: In Argentina, the dramatic facts and effects of the civil-military dictatorships have been largely addressed by social organizations, the State and Academia, given the significance human rights organizations have in the country. However, a particular situation arises with the Indigenous peoples: during civil-military dictatorships, this issue has been 
scarcely considered, turned invisible, and a lot (or almost everything) is still be done. We attempt to analyze these dynamics based on situations that involve the Mapuche population and community in the Argentine North Patagonia, more specifically, in the Nahuel Huapi National Park area (in the Andean region of the provinces of Rio Negro and Neuquén) with relation to the different evictions that took place during the suspension of constitutional guaranties during the 1950s, 1960s, and 1970s. Lastly, we will address the work of different university teams articulated with the original peoples, and how this has contributed to the visibility of these events as a fundamental part of the people's memory and identity.

KEYWORDS: Mapuche people; civil-military dictatorships in Argentina; Nahuel Huapi National Park; 1950s, 1960s and 1970s.

\section{Introducción}

Poco se sabía acerca de la familia Tacul, que daba el nombre a una de las siete "villas turísticas" que integran el Parque Nacional Nahuel Huapi $^{4}$-en la región cordillerana de Norpatagonia argentina ${ }^{5}-$, hasta que hace unos años, en 2007, los Tacul se establecieron en sus territorios ancestrales (la Villa Tacul) ${ }^{6}$. Con este accionar, reclamaron el

4 Un hito fundamental en el desarrollo de la región cordillerana fue la creación -mediante la Ley N. 12.103- de la Dirección (luego “Administración”) de Parques Nacionales, dependiente del Ministerio de Agricultura, fundada en el año 1934. En las adyacencias del lago Nahuel Huapi, se conformó el "Parque Nacional Nahuel Huapi" - primer área protegida de Sudamérica-, con sede en la ciudad de San Carlos de Bariloche - principal centro urbano de la región cordillerana de Norpatagonia-. Junto con el Nahuel Huapi, se creó el de Iguazú, y en 1937, el Parque Nacional Lanín. Históricamente, la Administración de Parques Nacionales jugó un rol sumamente protagónico en la construcción y consolidación del Estado en esta región. Consolidó - a partir de la arquitectura que se transformó en característica de la zona- la imagen de un área pretendidamente "natural", "virgen", con reminiscencias "alpinas", condensada en la imagen de una pretendida "Suiza argentina". Este imaginario promovido por la elite conservadora en las primeras décadas del siglo XX, contribuyó a profundizar el proceso de expulsión y negación de "chilenos" e "indígenas", y se acentuó así el proceso de estigmatización y persecución del cual ya eran objeto desde la conquista militar de estos territorios, a partir de la denominada "Conquista del Desierto", que tuvo lugar a fines del siglo XIX.

5 La Patagonia constituye la parte más austral de América del Sur. Comprende los territorios del sur de Chile y de la Argentina. En la Argentina, abarca un sector de la provincia de Buenos Aires, junto con La Pampa, Neuquén y Río Negro. Estos distritos corresponden al área norte de la Patagonia (Norpatagonia), región que abordamos en este trabajo. En cambio, la sección sur está compuesta por las provincias del Chubut, Santa Cruz y Tierra del Fuego (Ver Mapa n. ${ }^{\circ}$ 1).

6 Cuando se conformó el Parque Nacional Nahuel Huapi, en la década de 1930, se crearon siete "villas turísticas" con un perfil "europeizante" para residentes de alto poder adquisitivo. Estas son Villa Mascardi, 
reconocimiento como $\operatorname{comunidad}^{7}$ mapuche, bajo el nombre "Takul Chewque".

La recuperación de las tierras de la familia Tacul generó fuertes repercusiones en la opinión pública local y agudas controversias en diversos sectores sociales e institucionales (como el Municipio de Bariloche $)^{8}$. La zona en litigio constituye un área lujosa y muy codiciada por el turismo dentro del ejido municipal de la ciudad de San Carlos de Bariloche, ya que es cercana a la Villa Llao, cuya imagen más difundida es la postal turística del Hotel Llao LLao, donde se efectúan importantes cónclaves.

Al hacerse pública la historia de esta familia, se conoció un caso más -entre tantos- de despojos, privaciones y sufrimientos de la población que vive en los "barrios" populares de Bariloche (muy diferentes al área turística céntrica).

En 1902, le otorgaron a Ismael Tacul el permiso para residir en la zona que actualmente corresponde a Villa Tacul. A mediados de la década de 1950 (luego de la muerte de Ismael Tacul), Parques Nacionales desalojó a sus descendientes, quienes debieron trasladarse a la ciudad de Bariloche y comenzaron a vivir en uno de los barrios populares, donde padecieron situaciones de pobreza y discriminación.

Conflictos como el que aquí describimos son una muestra elocuente de la dinámica interétnica que lleva décadas en la zona, pero que se intensificó durante los últimos años. En efecto, el pueblo Mapuche ${ }^{9}$

Tacul, Rincón, Traful, Catedral, Llao Llao y La Angostura.

7 La organización comunitaria, que puede ser previa e independiente de la organización formal, se solicita en el Registro Nacional de Comunidades Indígenas (RENACI) del Instituto Nacional de Asuntos Indígenas (INAI), que depende, actualmente, de la Secretaría de Derechos Humanos y Pluralismo Cultural y el Ministerio de Justicia y Derechos Humanos.

8 Villa Tacul estaba, al momento del desalojo, bajo jurisdicción del Parque Nacional Nahuel Huapi, pero actualmente corresponde al Municipio de San Carlos de Bariloche, específicamente al Parque Municipal Llao Llao (ya que en la década de 1950 esta zona fue desafectada de Parques Nacionales y pasó a ser ejido municipal).

9 El pueblo Mapuche ('gente de la tierra' en su lengua originaria, el mapudungún) es uno de los grupos 
de Norpatagonia argentina (al igual que el de Chile) viene protagonizando movilizaciones y reivindicaciones en torno a sus territorios, su cultura y diversos derechos asociados a su pertenencia a un pueblo originario. Situaciones como las que vive el pueblo Mapuche nos revelan las historias que empiezan a conocerse y sobre las cuales, hasta hace pocos años, era muy escasa (o casi nula) la información con la que se contaba. También evidencian los avances en la interrelación que el pueblo Mapuche junto con otros sectores sociales e instituciones - como los propios ámbitos académicos - vienen fortaleciendo.

La problemática de los pueblos indígenas en relación con las dictaduras cívico-militares es una temática que suele estar negada, obliterada y sobre la cual hay muchísimo (o casi todo) por hacer. Por eso, en el marco del presente dosier: "Povos indígenas e ditaduras na América Latina" de la revista Espaço Ameríndio, nos proponemos ahondar en estas dinámicas. Antes de comenzar, debemos hacer algunas aclaraciones, para luego profundizar en tales períodos.

La historia de la antropología argentina en relación con los pueblos indígenas está cargada de paradojas y aspectos controversiales. En primer lugar, porque la propia historia nacional posee una configuración muy particular. En nuestro país, fue definitoria -en la consolidación estatal- una ideología positivista que ha plasmado en el imaginario colectivo el mito de una Nación de raigambre europea, que niega toda presencia indígena. Como reza un viejo dicho, a diferencia de los

originarios más importantes de la Argentina, aunque la gran mayoría reside en Chile. En dicho país, es el pueblo indígena más significativo: suman un millón de integrantes (JULIANO, 1996). Están asentados en la Octava, Novena y Décima Región (en el sur) y en la región Metropolitana (capital, en la zona centro) como resultado de las migraciones. En la Argentina, también es el pueblo más numeroso (más de 200.000 miembros), pero están más atomizados, junto con otros grupos originarios como el qom, kolla, diaguita, etc. (INDEC, 2012). El pueblo Mapuche se asienta en la Patagonia (la zona más austral de América del Sur), en las provincias del Chubut, Río Negro, Neuquén, La Pampa y Santa Cruz, en la provincia de Buenos Aires (RADOVICH, 2003) y, como resultado de las migraciones, en el Área Metropolitana de Buenos Aires (Ciudad y Gran Buenos Aires). 
peruanos que vinieron de los incas y los mexicanos de los aztecas, según esta perspectiva, "los argentinos vienen de los barcos" (RAMOS, 2011 , p. 9). Así, la construcción del relato acerca de los orígenes de nuestra Nación no surge, a diferencia de otros países de América Latina, de la "unión" o "mezcla" entre culturas, sino que se afirma que la población es presuntamente europea ${ }^{10}$.

En segundo lugar, y en directa relación con esto último, en la concepción del indígena como "externo" a la conformación nacional, el Estado-Nación configurado a fines del siglo XIX necesitó representarse - o construir a ese "nosotros" - en contraste con el "otro". Los pueblos originarios ocuparon ese lugar.

En efecto, para la denominada "Generación del 80" que fue clave en dicho proceso, la integración de la Argentina al sistema capitalista consistía en configurarse como productora de alimentos baratos para el desarrollo industrial europeo en auge. En este modelo, la ocupación tradicional de los territorios por parte de las comunidades indígenas era un obstáculo a superar. Tal proyecto de expropiación territorial, exterminio y/o confinamiento del indígena a través de las campañas genocidas de fines del siglo XIX necesitaba, desde ya, diversos mecanismos de legitimación que se basaron -en términos ideológicosen la construcción de estos grupos indígenas como supuestamente "bárbaros", "belicosos" y "enemigos internos". Para ello, el territorio donde residían los diferentes pueblos —el "Desierto"— fue representado como "lo opuesto a la civilización", es decir, un territorio de la "barbarie", lo cual creó una ideología nodal en el discurso justificatorio de la

10 En una entrevista efectuada en 1973 al reputado escritor Jorge Luis Borges en la revista masiva Siete Días, este afirmaba que en la Argentina no había población indígena "porque aquí matamos a todos los indios" (QUIJADA, 2000, p. 91). 
conquista (TRINCHERO, 2007; MASES, 2010; BALAZOTE, 2015; BARTOLOMÉ, 2003; QUIJADA, 2000).

Tal como hemos señalado a lo largo de años de investigaciones (TRINCHERO, 2000; 2007 y 2010), los pueblos indígenas se convirtieron en el principal "enemigo interno" que la modernidad inventó para legitimar su expansión sobre el territorio (TRINCHERO, 2007; TRINCHERO; VALVERDE, 2014). Esto explica que, en el caso argentino, el genocidio de los pueblos indígenas se haya erigido como "fundante de la Nación”. En muchos ámbitos del país, se exaltaba y ritualizaba (y aún se lo sigue haciendo) la "guerra contra el indio" como presunto inicio de la "civilización", cuya condición sería la "extinción" del indígena (TRINCHERO, 2007; TRINCHERO; VALVERDE, 2014).

Al mismo tiempo, para la "Generación del 80", cuyo papel fue central en la conformación del Estado-Nación argentino, esta diversidad se tornaba "anárquica" y "subversiva" en la medida en que lo heterogéneo carecía - para su diseño clasificatorio- de una ubicación explícita dentro de la producción de un orden simbólico, a la vez determinante para construir y legitimar un orden económico y político (BALAZOTE, 2015).

El tercer aspecto paradójico de la relación de la antropología con los pueblos originarios en nuestro país nos retrotrae a la última dictadura cívico-militar (1976-1983). Durante este período, los pueblos indígenas se convirtieron en el objeto de reflexión antropológica por excelencia, y se negaron otros sujetos, realidades y geografías a abordar.

En efecto, los trabajos antropológicos se centraron casi exclusivamente en la región chaqueña, que se consideraba el ámbito "natural" de pertenencia de esos "otros". Es decir, el "Desierto", tan caro a la conformación nacional. Esta representación fue promovida y recreada por la antropología dominante en aquellos oscuros años, la denominada 
"Escuela fenomenológica de la Antropología Argentina", dirigida por Marcelo Bórmida".

En cuarto lugar, otra controversia se dio con el retorno de la democracia (a partir de 1983). Desde ese momento, el estudio de los pueblos indígenas fue virtualmente abandonado como problemática de estudio en el ámbito local, ante las dificultades que les presentaba a los antropólogos $-\mathrm{y}$, en especial, a las nuevas generaciones- abordar la temática sin replicar o ser acusados de reproducir el esquema bormidiano. Precisamente, cuando resultaba imperioso analizar la realidad de los pueblos indígenas a partir de esquemas innovadores que contrastaran con los desarrollados durante la dictadura, se produjo un "vacío" de teorías y aproximaciones en relación con el tema.

Esto sucedía al mismo tiempo que se configuraba un "reconocimiento", por parte del Estado, de ciertos derechos de los pueblos indígenas de la Argentina, a través de una serie de dispositivos y disposiciones jurídicas.

No obstante, debemos destacar que, durante aquellos años, diferentes teóricos buscaron nuevos enfoques para abordar la realidad de los pueblos originarios de nuestro país, y paulatinamente afianzaron las nuevas perspectivas.

Por último, cabe señalar que en la Argentina, los dramáticos hechos y efectos que las dictaduras-cívico militares provocaron han sido largamente abordados por variados sectores, organizaciones sociales, el Estado y los ámbitos académicos, —dado, además, el peso (sin precedentes en el resto del mundo) que han tenido en nuestro país las organizaciones de Derechos Humanos-. Sin embargo, una situación particular se plantea con los pueblos indígenas: la suerte de estos durante 
los períodos de dictaduras cívico-militares es una temática que, tal como hemos señalado, ha sido escasamente tratada, suele estar invisibilizada y sobre la cual hay muchísimo (o casi todo) por hacer.

Debemos rememorar lo que sucedía con los pueblos indígenas en aquel momento: a pesar de las políticas homogeneizadoras y negadoras de la diversidad que predominaron durante el siglo $X X$, en la década de $1970^{12}$, comenzaron a emerger diversas organizaciones indígenas. Luego, con el retorno de la democracia (en la década de 1980) los grupos originarios irrumpieron en la escena pública con una presencia inusitada. Uno de los fenómenos más destacados en términos sociales, políticos y culturales de las últimas décadas, en América Latina $-\mathrm{y}$ también en la Argentina- fue la emergencia de los pueblos indígenas en la arena pública y su participación como sujetos sociales y políticos (ITURRALDE, 1991; BENGOA, 2007).

En las décadas subsiguientes, se fue dando una consolidación de las organizaciones indígenas, la afirmación de estos procesos organizativos, las articulaciones con otros sectores sociales y un lento pero paulatino reconocimiento de sus demandas por parte de diversos niveles estatales.

12 El período desde fines de la década de 1960 y principios de 1970 fue clave en la formación del movimiento indígena nacional (RADOVICH, 2014). El Centro Indígena de Buenos Aires (CIBA) fue creado en 1968 por un grupo de dirigentes. Luego, se convirtió en la Comisión Coordinadora de Instituciones Indígenas de la Argentina (CCIIRA). En 1973, se organizó un Congreso Indígena Nacional que disolvió la CCIIRA y dio origen a la Federación Indígena de la Capital Federal y el Gran Buenos Aires. Esta última se mantuvo hasta 1975, cuando el terrorismo de Estado comenzó a perseguir a sus referentes. En este período de dictadura cívico-militar, las organizaciones desmanteladas conformaron la Asociación Indígena de la República Argentina (AIRA), y se centraron en reivindicaciones vinculadas más con lo cultural que con lo económico y político (SERBIN, 1981; RADOVICH, 2014).

En la Patagonia, se destaca un antecedente organizativo en la década de 1970: la Confederación Indígena Neuquina (CIN), una de las primeras agrupaciones del país. La CIN tuvo un rol destacado en la organización del Primer Parlamento Indígena Nacional, que se celebró en Neuquén en 1972. En él participaron representantes de pueblos de diversas etnias del país (FALASCHI, 1994). A partir del año 1974, el fuerte contexto represivo sobre las organizaciones populares en la Argentina hizo que la CIN perdiera fuerza y fuera políticamente cercada por el Gobierno provincial (SERBÍN, 1981). Luego, en la década de 1980, este grupo pasó a tener una presencia cada vez más destacada. Desde entonces, se denomina Confederación Mapuche Neuquina. 
En contraste con la tendencia que primó durante buena parte del siglo $X X$, en la que prácticamente no se avanzó en el reconocimiento de los derechos de los pueblos originarios sobrevivientes al genocidio ni a las posteriores masacres ${ }^{13}$, se fueron incorporando diferentes variantes del concepto de "participación" de las organizaciones indígenas en los entes estatales o en las reparticiones creadas al efecto (GOROSITO KRAMER, 2008).

Este distanciamiento entre los pueblos indígenas y la antropología argentina -temática devenida en un tema "maldito"- empezó a revertirse con los "contrafestejos" de la conmemoración del V Centenario de la Conquista de América, en 1992.

Esto permitió un acercamiento de académicos a dirigentes, organizaciones y comunidades indígenas ${ }^{14}$. Por otro lado, variados ámbitos institucionales empezaron a demandar la asistencia profesional de diversos antropólogos en relación con este tema.

En el presente artículo, nos proponemos, en primer lugar, abordar el tratamiento de la cuestión indígena desde la antropología producida en la Argentina durante la última dictadura cívico-militar y, en segundo lugar, analizar el cambio de esos abordajes en la disciplina a partir del retorno de la democracia y, en particular, desde el 2000 en adelante. En relación con este último aspecto, nos centraremos en las

13 Una excepción se dio durante el Gobierno del General Perón, con la Constitución de 1949 y el denominado "Estatuto del Peón" que son, tal vez, sus claves políticas más representativas para el sector (TRINCHERO, 2010).

14 Un antecedente importante en este sentido es el Programa Permanente de Extensión, Investigación y Desarrollo en Comunidades Aborígenes dirigido por H. H. Trinchero en el marco de la Universidad de Buenos Aires. Este programa se originó en 1994 como resultado de un trabajo conjunto y consensuado entre miembros de las comunidades aborígenes de la región del Chaco centro-occidental, miembros de la Sección Antropología Social del Instituto de Ciencias Antropológicas, de la Secretaría de Extensión Universitaria (SEUBE) de la Facultad de Filosofía y Letras de la Universidad de Buenos Aires (FFyL-UBA) y organizaciones solidarias. A lo largo de años de acciones en común, el objetivo general del programa ha sido vincular y articular, en forma sistemática y permanente, proyectos y actividades de investigación en distintos campos del conocimiento con acciones de fortalecimiento comunitario, capacitación y práctica solidaria. 
transformaciones que se produjeron a partir de la consolidación de las organizaciones y comunidades indígenas junto con la sanción de una serie de legislaciones que implicaron un reconocimiento de estos pueblos y los convirtieron en sujetos de derecho.

Paralelamente, otra variación fundamental se asocia con las crecientes articulaciones de los ámbitos académicos con diversos sectores sociales -entre ellos, los pueblos originarios- que tuvieron lugar a partir de las políticas de ampliación de derechos, con el consiguiente incremento de la inversión en políticas públicas durante las presidencias de Néstor Kirchner (2003-2007) y Cristina Fernández de Kirchner (2007-2011 y 2011-2015). Entre las acciones que se desarrollaron desde diferentes ámbitos oficiales, podemos mencionar las del Ministerio de Educación y las de la Secretaría (y luego Ministerio) de Ciencia y Técnica, las cuales significaron un marcado contraste con las políticas neoliberales de la década de 1990.

Ahondaremos en el trabajo articulado de diferentes equipos universitarios y ámbitos académicos con los pueblos originarios, y en cómo esta colaboración ha contribuido a visibilizarlos. Como parte de estas dinámicas, analizaremos de qué manera estas relaciones han colaborado a echar luz sobre la forma en que se vienen recuperando diversas trayectorias y situaciones dramáticas que protagonizaron los pueblos indígenas durante las dictaduras cívico-militares. A la vez, entendemos que las producciones académicas generadas durante los períodos dictatoriales fueron parte fundamental de la negación y estigmatización. A partir de situaciones que involucran a poblaciones y comunidades del pueblo indígena Mapuche en Norpatagonia argentina, específicamente en la zona del Parque Nacional Nahuel Huapi (departamento Los Lagos, provincia del Neuquén y departamento 
Bariloche, provincia de Río Negro), ejemplificaremos diferentes desalojos y otros hechos que tuvieron lugar durante los años en que estuvieron suspendidas las garantías constitucionales (ver mapa adjunto).

Paralelamente, retomaremos el tema de la recuperación de la memoria colectiva como una forma de dar a conocer los hechos y, a la vez, darles visibilidad a las reivindicaciones que vienen planteando las organizaciones indígenas y sociales.

Brevemente, señalaremos que en la Argentina residen más de 40 pueblos originarios, que suman, aproximadamente, un millón de integrantes (sobre una población de más de cuarenta millones de argentinos).

Como mencionamos anteriormente, con el devenir democrático (en 1983) y, en particular, durante los últimos años, los indígenas fueron consolidando sus organizaciones y generando profundos cambios en la sociedad en su conjunto, al igual que en los diferentes ámbitos institucionales. Durante las últimas décadas, en Norpatagonia -al igual que en el resto de la Argentina y de América Latina- se acrecentó la organización y presencia del pueblo Mapuche a través de diversos movimientos. El rol de estos últimos ha sido clave, dado que vienen enfrentando la narrativa del Estado-Nación argentino. En estrecha asociación con estos procesos organizativos, se incrementaron los litigios con inversores privados y algunos niveles del Estado. A raíz de esto, se registraron situaciones de gran conflictividad, tendencia que coincide plenamente con la de otros grupos indígenas y pequeños productores rurales a lo largo del país (TAMAGNO, 2012).

Para el desarrollo de este artículo, recuperamos la experiencia de las investigaciones y labores que venimos realizando desde hace años. 
El primero de los autores -Hugo Trinchero- trabaja, desde mediados de la década de 1980, en el Norte argentino. Allí ha indagado en torno al proceso de conformación del Estado-Nación, a la constitución de las fronteras (políticas, económicas y socioculturales) y a las transformaciones resultantes entre las poblaciones originarias. $\mathrm{Ha}$ dirigido numerosos proyectos (UBA, CONICET, etc.) y publicado múltiples trabajos en relación al tema. Es director de un programa de investigación ${ }^{15}$ del Instituto de Ciencias Antropológicas, de la Facultad de Filosofía y Letras de la Universidad de Buenos Aires.

Ivanna Petz cuenta con amplia experiencia en la articulación de la universidad con otros sectores de la población. Publicó diversas reflexiones teórico-metodológicas sobre este vínculo. Además, dirigió proyectos de extensión o transferencia (de la Universidad de Buenos Aires y de la Secretaria de Políticas Universitarias). Actualmente, es Secretaria de Extensión Universitaria y Bienestar Estudiantil (SEUBE) de la Facultad de Filosofía y Letras de la Universidad de Buenos Aires y ha sido coordinadora - y una de las fundadoras - del Centro de Innnovación y Desarrollo para la Acción Comunitaria (CIDAC), con sede en el barrio de Barracas, en la zona sur de la Ciudad de Buenos Aires.

Por último, Sebastián Valverde investiga, desde hace más de una década, en relación con el pueblo Mapuche en Norpatagonia, Argentina, en especial los movimientos indígenas, las transformaciones socioeconómicas regionales y sus impactos en dichas poblaciones, y la conflictividad territorial asociada a estos cambios. Dirige diversos proyectos (UBACYT y PDTS-CIN-CONICET, etc.) en el programa de investigación ya mencionado ${ }^{16}$. También ha dirigido proyectos de

15 Programa "Economía política y formaciones sociales de frontera. Etnicidades y territorios en redefinición", Sección Antropología Social, Instituto de Ciencias Antropológicas, Facultad de Filosofía y Letras, Universidad de Buenos Aires.

16 Idem nota al pie anterior. 
extensión y transferencia (o extensión) a través de diversos proyectos de Voluntariado Universitario y de extensión de la UBA (UBANEX). También, en estos últimos proyectos, viene trabajando con población indígena migrante en el Área Metropolitana de Buenos Aires (AMBA), de los pueblos guaraní, diaguita kolla, mocoví y qom.

\section{Mapa No 1: República Argentina}

\section{Mapa No 2: Región cordillerana, Parques Nacionales Lanín y Parque Nacional Nahuel Huapi}

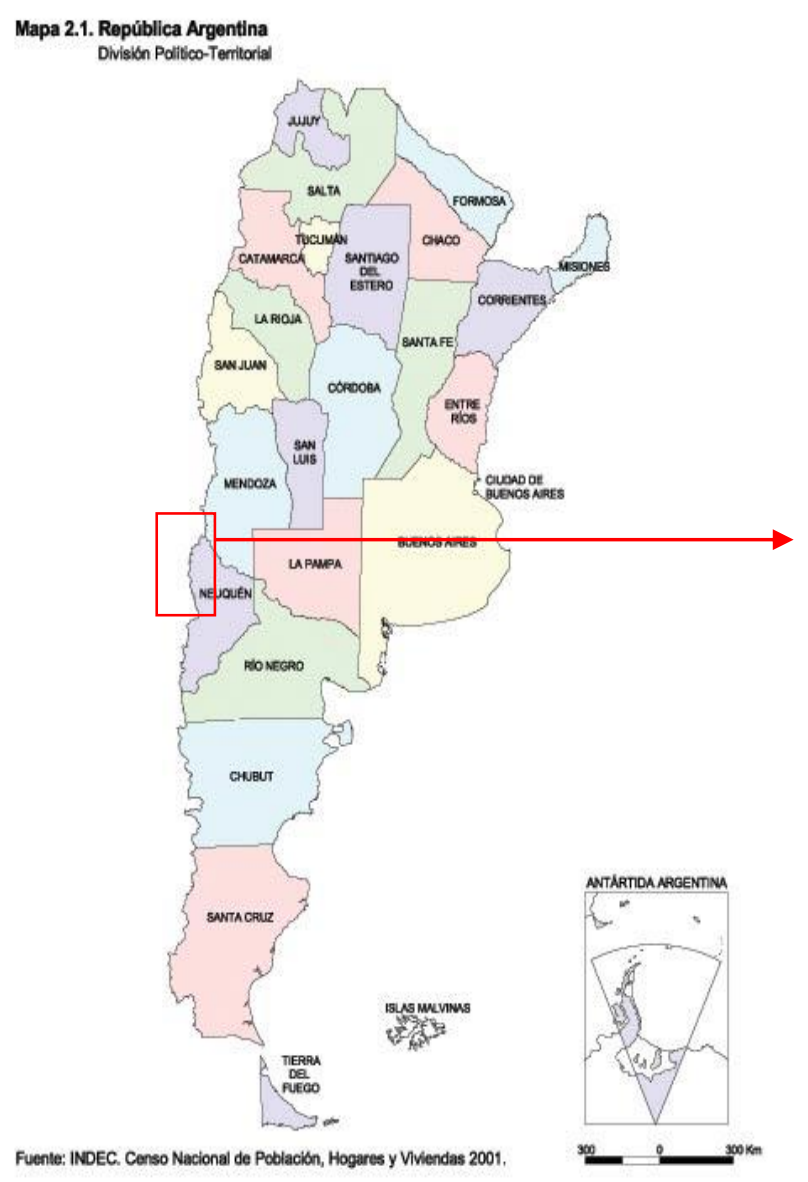

Fuente: Carta Topográfica de la República Argentina. Ejército Argentino. Instituto Geográfico Militar, 1947.

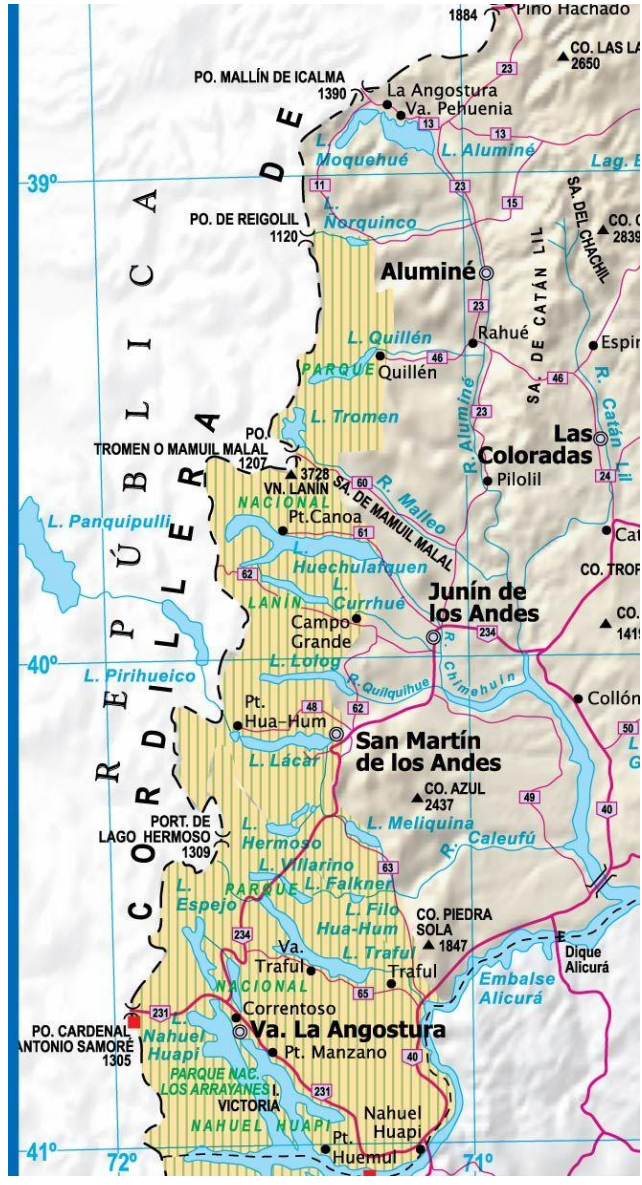

Fuente: Ministerio de Educación, Ciencia y Tecnología. Informe de gestión 2003-2007. Ciudad Autónoma de Buenos Aires, 2007. 


\section{La antropología de la escuela fenomenológica y el abordaje de la cuestión indígena}

Para poder profundizar en torno a la antropología desarrollada durante la última dictadura-civico militar, debemos hacer mención a las corrientes que fueron hegemónicas por aquellos oscuros años. Mundialmente, la denominada escuela "histórico-cultural" o "difusionista" se fue desarrollando desde los últimos años del siglo XIX hasta las primeras décadas del siglo XX, principalmente en Estados Unidos, Alemania e Inglaterra. Sus referentes más destacados fueron Graebner (1877-1942), Smith (1864-1922), Wissler (1870-1947) y Rivers (1864-1922) (Ramos et al. 2006) ${ }^{17}$.

En lo que respecta a la Argentina, en general existe un consenso en considerar el período que va de 1930 a 1950 como el de supremacía de la escuela histórico-cultural de cuna austríaca y alemana (RATIER, 2010; PERAZZI, 2009). En la década de 1950, se desarrollaron diferentes estudios arqueológicos en esta escuela, donde desempeñó un rol fundamental Osvaldo Menghin ${ }^{18}$. Otro referente de esta línea fue Marcelo Bórmida, joven antropólogo físico italiano, oficial de Mussolini durante la contienda (RATIER, 2010). Así, Menghin fue consolidando su presencia en la Universidad de Buenos Aires (en el aérea de arqueología en la Patagonia)

17 Esta escuela consideraba la presencia de un foco o centro cultural que irradiaba una serie de ondas concéntricas de "influencias" que alcanzaban — luego de cierto tiempo y de extenderse en el espacio- a otros grupos humanos. Las invenciones se realizaban en ese "centro primario" que influía sobre las áreas secundarias externas, esto es, la denominada "difusión cultural", que puede darse a partir de diferentes factores como el contacto, la migración y la invasión (RAMOS et al, 2006). Aunque se admita que el principio de difusión puede ser de utilidad para relacionar rasgos culturales, es incapaz de dar cuenta del origen de los rasgos culturales, a no ser que se llegue a una regresión infinita y absurda. De hecho, la explicación del cambio, atribuyéndolo exclusivamente a la "migración" o "difusión" de patrones culturales "externos", nos ubica en un punto paradójico: ¿cuál sería entonces el "origen” de dicho rasgo?, ¿cómo se produce el cambio cultural?, ¿solo ocurre por difusión o existen también factores internos? (HARRIS; 1994; RAMOS et al, 2006).

18 Menghin fue un destacado prehistoriador austríaco que se instaló en nuestro país en 1948, ya que sus vinculaciones con el nazismo lo obligaron a exiliarse luego de la Segunda Guerra Mundial. 
y su discípulo, Marcelo Bórmida, (especializado en etnología) lo acompañaba en sus expediciones (RATIER, 2010). Parafraseando a este último autor, estos investigadores "trataban al indígena como mera fuente de datos históricos sin la menor preocupación por la realidad presente" (RATIER, 2010, p. 26). Al decir de Herrán, para esta corriente, los grupos indígenas "Son pueblos objeto, que sólo cobran sentido al ser construidos por el antropólogo: en suma 'pueblos etnográficos'” (1990, 111).

Entre 1958 y 1959, con los intentos de "modernización" del país, se conformaron organismos como el Consejo Nacional de Investigaciones Científicas y Técnicas (CONICET) y se crearon nuevas carreras como Psicología, Sociología, Ciencias de la Educación y la que nos interesa destacar particularmente: Antropología. Esta carrera comenzó a dictarse en Buenos Aires, Rosario y La Plata. Por lo tanto, se dio un proceso de "profesionalización" del quehacer antropológico que generó, posteriormente, profundas transformaciones. Sin embargo, este cambio no modificó la orientación de la antropología aquellos años, en los que la corriente difusionista siguió detentando un lugar hegemónico (RATIER, 2010).

A partir de 1962, los primeros graduados de la novel carrera de Antropología plantearon una ruptura con las concepciones elitistas y asumieron el compromiso con la realidad nacional y las capas sumergidas de la sociedad. Así, surgió una nueva generación que empezó a adherir a la denominada "antropología social", que nació como opuesta a la corriente historicista que la enfrentaba taxativamente. Sus adherentes no pertenecían a una única línea sino, por el contrario, a varias: estructural funcionalismo, estructuralismo y neo-marxismo (RATIER, 2010, p. 32). Esta generación se involucraba en el trabajo en proyectos e 
instituciones -por ejemplo, el Instituto Nacional de Tecnología Agropecuaria (INTA)-, a través de perspectivas novedosas desde el punto de vista teórico y con un abordaje interdisciplinario (con agrónomos, médicos, arquitectos, etc.), lo que contribuyó a la apertura hacia nuevas miradas (RATIER, 2010). En contraste con estas alternativas, la orientación de la enseñanza hegemonizada por la escuela histórico-cultural: “(...) sigue siendo la investigación antropológica como reconstrucción histórica hipotética. De indígenas o criollos, lo que interesa - se enseña- es aquello que conservan del pasado, no su realidad presente" (RATIER, 2010, p. 31).

Las propias palabras de Marcelo Bórmida a mediados de la década de 1950, son más que elocuentes acerca de los preceptos de esta corriente:

Las culturas primitivas nos permiten penetrar a fondo en el mundo espiritual del hombre prehistórico...Cada una de ellas es el eco de una época remota de la humanidad, que es el peldaño obligatorio de nuestra propia cultura (BÓRMIDA, 1956 apud HERRÁN, 1990, p. 109).

Con el golpe de estado de 1966, Marcelo Bórmida adquirió el predominio absoluto, no solo en la Universidad de Buenos Aires, sino también en otros ámbitos vitales como el CONICET. Al mismo tiempo, la nueva generación orientada hacia la antropología social se vio obligada a buscar rumbos alternativos.

En el interregno democrático de 1973-1976, se desarrollaron destacadas investigaciones desde estas perspectivas, centradas en la antropología social, cuando las nuevas generaciones volvieron a ocupar ámbitos universitarios. Pero con el incremento de la represión política hacia fines de 1974 y durante 1975, estas experiencias tuvieron que Ilamarse a silencio y esta generación debió partir al exilio (HERRÁN, 1990, 
p. 113-114).

A partir de la intervención, a fines de 1974, de la Facultad de Filosofía y Letras de la Universidad de Buenos Aires, predominó la denominada "escuela fenomenológica de la antropología argentina" -hegemonizada por Bórmida hasta su muerte, en 1979-. Él había producido, entre 1969 y 1970, un cambio en la vertiente histórico-culturalista, dado que aquellos años privilegió el estudio de aspectos descontextualizados de la realidad y efectuó una lectura muy particular de la "fenomenología", que negaba toda teoría y buscaba recuperar la "conciencia mítica" de los indígenas, como forma de llegar a las "esencias culturales". Es evidente que esta exigencia al etnógrafo de deponer todo aquello que estuviera vinculado a su posición teórica previa (como si eso fuera posible) (BALAZOTE; RADOVICH, 2010) resultaba particularmente agradable al régimen represivo imperante (RATIER, 2010, p. 34-36).

Esta línea teórica continuó hasta el retorno de la democracia en el año 1983, mientras la Antropología Social permanecía vedada dentro de las Universidades y de los organismos de Ciencia y Técnica. Bartolomé y Radovich (2014) han destacado que el grupo conformado por Bormida y sus discípulos:

Controló las posiciones y las investigaciones antropológicas durante el sangriento proceso militar y transformó los estudios sobre poblaciones indígenas en precarias recopilaciones de mitos, huérfanas de contextos sociales y de análisis interpretativos (2014, p. 242).

Eduardo Menéndez (2008) en su crítica a la Antropología desarrollada por aquellos años -como uno de los primeros egresados de la carrera de antropología, destaca como un hecho nodal “(...) la 
exterminación intencional por los dueños de la tierra de onas, yaganes, alacalufes y, en menor medida, de personas de otros grupos étnicos" (2008, p. 93). Y aquí introduce su crítica, cuando señala “(...) en nuestra carrera de Ciencias Antropológicas ningún profesor hablaba de este tipo de episodios, de estos asesinatos intencionales de grupos étnicos" (MENÉDEZ, 2008, p. 93). En la misma línea hemos efectuado una temprana critica (TRINCHERO, 2000) al señalar como desde semejante aproximación, la subjetividad aborigen (supuestamente) desconocía la categoría "trabajo". Como señalábamos en aquella oportunidad, estas producciones "estaban muy lejos de ser ingenuas o producto meramente de concepciones filosófico-antropológicas discutibles" (2000, p. 27).

\section{El rol de la universidad en relación con la diversidad y los pueblos originarios en las últimas décadas}

Hacia fines de 1990, la sociedad argentina fue protagonista de una aguda crisis política, económica y social como resultado de la aplicación de diferentes políticas neoliberales instrumentadas en las presidencias de Carlos S. Menem (1989-1995 y 1995-1999) y Fernando De la Rúa (1999-2001). A lo largo de la década de 1990, se incrementó el desempleo, se vivieron procesos de precarización y flexibilización laboral y se implementó una política económica basada en el endeudamiento externo que permitió mantener el régimen de convertibilidad que sostenía la paridad peso-dólar.

En diciembre de 2001, ante la extracción masiva de depósitos de los ahorristas ${ }^{19}$, la creciente recesión económica, la dificultad para 
conseguir financiamiento internacional (en dólares) y el desempleo junto con la ascendente movilización de vastos sectores sociales, se profundizó la crisis. Hacia mediados del mes, se produjeron saqueos a comercios y grandes supermercados por parte de sectores pauperizados, que, junto con las movilizaciones masivas de clase media y vastos sectores populares, el 19 y 20 de diciembre desencadenaron, represión mediante, la renuncia del presidente De la Rúa ${ }^{20}$. Dichas jornadas configuraron un acontecimiento político en el que se pusieron en cuestión, masivamente, en las distintas ciudades del país, las políticas neoliberales. Expresaron contundentemente la crisis de un proceso hegemónico. Para los sectores dominantes, tal movilización fue analizada en términos de una crisis inédita de gobernabilidad. Para los sectores dominados, que venían planteando la lucha en términos reivindicativos, implicó la posibilidad de avanzar hacia un marco de mayor protagonismo político y volver a poner al Estado en sus debates, lo que no es otra cosa que volver al "... problema fundamental de la política que es el problema del poder" (CARRI, 1967, p. 187 apud PETZ, 2010, p. 184).

Luego, fueron meses de gran crisis política-institucional ${ }^{21}$ y económica, que comenzó a revertirse a partir de la presidencia de Néstor Kirchner (2003-2007) quien, ya en el discurso de su asunción, expresó las claves de su política e introdujo una serie de demandas y reivindicaciones levantadas por las organizaciones de Derechos Humanos y sectores populares. Se hizo cargo de los alcances y las limitaciones de las luchas de su generación, y ubicó los términos de su política económica y de la

extraer del sistema bancario. Este hecho generó un gran descontento entre los ahorristas (mayoritariamente, de clase media) y una drástica reducción del dinero circulante que contrajo (aún más) la economía.

20 La represión estatal durante esas jornadas, en todo el país, generó muertes, encarcelamientos, torturas, secuestros e innumerables heridos.

21 Bajo la consigna "que se vayan todos", se aglutinaron distintos sectores y lograron condicionar a la elite política exponiendo sus fragilidades y divisiones con una inédita sucesión de cinco presidentes provisionales en pocas semanas. 
política regional e internacional. Después de ese discurso y de las primeras acciones políticas, el 22 \% de popularidad con el que había asumido ascendió rápidamente y llegó, unos meses después de iniciar su mandato, a un $60 \%$. En Latinoamérica, quedó claro que con el apoyo de Fidel Castro y de Hugo Chávez, el entonces presidente Kirchner se alineó en el gran frente de repudio al neoliberalismo.

Desde entonces, se inició, en la Argentina una etapa de importantes transformaciones político-económicas y socio-culturales, particularmente a partir de la redefinición del rol de Estado. Estas transformaciones continuaron y se profundizaron durante las presidencias de Cristina Fernández (2007-2011 y 2011-2015).

En tanto institución del Estado, la universidad resultó fuertemente interpelada, tanto en sus misiones clásicas de docencia, investigación y extensión, como en relación con su carácter autónomo, su rol estratégico para el desarrollo nacional y sus definiciones de "excelencia" (en ocasiones, ambiguas y discutibles) (PETZ et al, 2016).

Se fueron instrumentando diferentes programas, tanto desde el Ministerio de Educación de la Nación —en especial, desde la Secretaría de Políticas Universitarias: Voluntariado Universitario ${ }^{23}$, Universidad Estado y Territorio, Vinculación Tecnológica, entre otros- como desde las universidades nacionales que, desafiadas respecto de su relevancia social,

\footnotetext{
22 En el campo popular organizado, las repercusiones fueron muy positivas, ya que generaron expectativas que se expresaron más tarde en la definición política de acompañar el proceso abierto a partir del 25 de mayo de 2003

23 El programa de Voluntariado Universitario se creó en 2006. Desde entonces, se abren concursos ordinarios para financiar proyectos. A partir de 2009, se incorporaron convocatorias específicas que buscan articular los proyectos con políticas públicas novedosas, como es el caso del programa "Conectar Igualdad" - política de inclusión digital de alcance federal— o temáticas vinculadas a la coyuntura anual, como las convocatorias "Bicentenario" (2010) y "La Patria es el Otro" (2013). Asimismo, en las convocatorias ordinarias, los ejes temáticos para presentar proyectos fueron ampliándose también en función de las problemáticas que surgieron en los territorios. Entre los que más se destacaron, podemos mencionar economía social, trabajo y cooperativismo, juventud, pueblos originarios, promoción de la salud, cultura, medios audiovisuales, democracia, inclusión social, cultura, historia e identidad nacional y latinoamericana, entre otros.
} 
implementaron novedosos subsidios a la Extensión Universitaria (la programación UBANEX, en el caso de la Universidad de Buenos Aires a la cual pertenecemos). En general, el sentido de estos programas apuntó a la promoción de la vinculación territorial de la universidad, entendiendo que los saberes académicos constituyen un valor determinante para mejorar las condiciones de vida del conjunto de la sociedad, especialmente, de los más humildes (ALONSO, 2015).

Este cambio sustancial fue factible gracias al incremento del presupuesto de educación encarado por las gestiones presidenciales que antes mencionamos.

En 2003, el presupuesto del Ministerio de Educación era de 14.500 millones de pesos, que equivalían al 3,86 \% del PBI nacional. En 2012, llegaba a los 140.611 millones de pesos, que implicaban, en ese momento, el 6,50 \% del PBI nacional ${ }^{24}$. La vocación de convertir esta tendencia en política a largo plazo se expresó en la Ley de Financiamiento Educativo N.2 26.075 (LFE), que en diciembre de 2005 estableció la meta del $6 \%$ de inversión del PBI en materia de educación, ciencia y tecnología para 2010. De acuerdo con el análisis de Bezem, Mezzadra y Rivas (Repetto, 2014), esta norma marcó un hito en la educación argentina, ya que favoreció el aumento de la inversión en el sector (REPETTO, 2014). Un año más tarde, la Ley de Educación Nacional N. 26.206 (LEN) ${ }^{25}$ fue más

\footnotetext{
24 Jornadas Nacionales de Educación 2003-2013. La década ganada. Presidencia de la Nación, 2013. 25 Esta ley fue sustancialmente importante, ya que derogó los puntos más sobresalientes de la fracasada Ley Federal de Educación. Algunos de los puntos centrales de esta nueva ley (en cuanto a los intereses de este escrito), se presentan en el Artículo 9: en consonancia con lo que plantea en el cuerpo central del texto, propone que el financiamiento de la educación no esté por debajo del $6 \%$ del PBI nacional. Por otra parte, el Artículo 10 impide tratados bilaterales o multilaterales de libre comercio que consideren a la educación como un servicio lucrativo o que tiendan a mercantilizarla. La educación se considera un derecho humano y se la corre del eje que prevaleció en la década de 1990, cuando la educación se subsumía casi exclusivamente a las exigencias del mercado. Por último, son relevantes el Artículo 16, que extiende la obligatoriedad escolar desde los cinco años hasta finalizar el nivel secundario, y el Capítulo IX de "educación permanente de jóvenes y adultos". Estos últimos, junto con otras medidas, favorecieron la creación de contextos que posibilitan el acceso a los niveles de educación superior para el conjunto de la población, incluyendo aquellos que, aun por encima de la edad escolar, pudieron terminar sus estudios por medio de distintas políticas que el Capítulo IX permitió generar.
} 
allá y estableció que ese porcentaje debía ser destinado exclusivamente a la educación, y ciencia y tecnología debían tener un presupuesto propio. Hacia 2009, las metas propuestas en la LFE (26.075) y en la LEN (26.206) fueron superadas ampliamente, tal como se ve en el siguiente gráfico:

Gráfico 1: Progresión del presupuesto en educación. Años 2003-2013

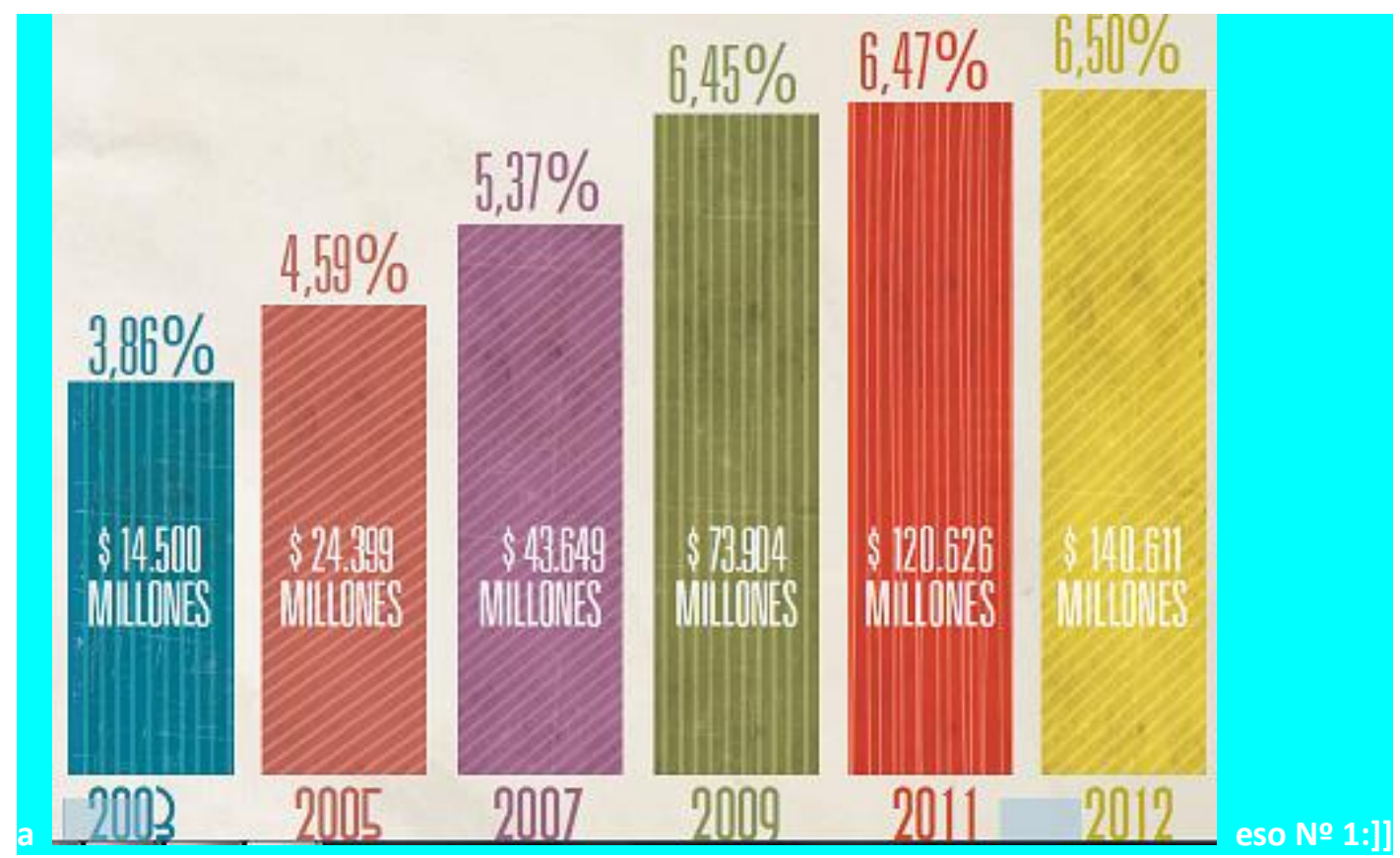

Fuente: Jornadas Nacionales de Educación 2003-2013. La década ganada. Presidencia de la Nación, 2013.

Para dimensionar la transformación en la política de educación superior, es necesario señalar que hasta la década de 1950 solo había en el país seis universidades nacionales. Actualmente, el Consejo Interuniversitario Nacional (CIN) reconoce 53 , de las cuales quince fueron creadas en los últimos años con el objetivo de modificar la matriz elitista que caracterizó el acceso a las universidades nacionales. El eje orientador de la política de educación superior de los Gobiernos del período 2003-2015 $5^{26}$ fue la necesidad de universidades federales -es decir, 
vinculadas a sus territorios-, y una concepción de la educación como herramienta igualadora.

Podemos mencionar también las acciones más recientes del Ministerio de Ciencia y Técnica ${ }^{27}$ en pos de generar resultados para la sociedad en su conjunto (es decir, que trasciendan los ámbitos académicos). Se trata de los Proyectos de Desarrollo Tecnológico y Social (PDTS) instrumentados por las universidades nacionales a través del Consejo Interuniversitario Nacional (CIN) y el Consejo Nacional de Investigaciones Científicas y Técnicas (CONICET) ${ }^{28}$. Los nuevos criterios de evaluación del personal científico y tecnológico buscan establecer una ponderación más equilibrada entre la ciencia básica y la ciencia aplicada, con el objetivo de incentivar que las investigaciones se conviertan en desarrollos concretos, prototipos o productos (PETZ et al, 2016).

En oposición a las posturas de neto carácter academicista que tienden forzar una separación entre estas instancias, con la promoción de convocatorias a proyectos de investigación y desarrollo (I+D) en las líneas que caracterizamos anteriormente, se asiste a un proceso que recupera un problema típico del campo de la filosofía de la ciencia: ¿es posible establecer una disyunción entre ciencia básica y ciencia aplicada? Desde el positivismo, se suele referenciar a la ciencia básica como comprometida exclusivamente con valores cognoscitivos, por lo que

Latinoamericanas. Buenos Aires: Editorial de la Facultad de Filosofía y Letras de la Universidad de Buenos Aires.

27 Desde 2003, se le asignó un rol estratégico a la ciencia y la tecnología, y se configuraron como política de Estado. Esto se ratifica en relación con la inversión y, en la institucionalidad, con la creación del Ministerio de Ciencia, Tecnología e Innovación Productiva (MINCyT) a través de la Ley Nacional N. ${ }^{\circ}$ 26.338, hacia finales de 2007. Desde entonces, comenzaron a implementarse y fortalecerse un conjunto de lineamientos estratégicos que incluyen el fortalecimiento, la federalización y la articulación efectiva del sistema nacional de ciencia, tecnología e innovación; el fortalecimiento en infraestructura, recursos humanos y capacidades; el delineamientos de programas que aborden las áreas problemáticas (productivas y sociales), estratégicas (biotecnología, nanotecnología, TIC) y sectores prioritarios (salud, energía, desarrollo social y agroindustria) diagnosticados y definidos en el período 2003-2007; y la efectivización de políticas de divulgación de la ciencia (INNOVAR, Tecnópolis) (PETZ et al, 2016).

28 A partir de 2012, se conforma el Banco Nacional de Proyectos de Investigación y Desarrollo Tecnológico (PETZ et al, 2016). 
cualquier otro tipo de compromiso es considerado espurio. La ciencia aplicada, por su parte, encuentra otras fidelidades. Según Mario Bunge (1984), el investigador aplicado estudia solamente problemas de posible interés social y se le puede encargar que lo haga con el fin de resolverlos. De esta manera, su compromiso no es exclusivamente con el conocimiento, si se puede suponer como una actividad fuera de todo compromiso social.

Esta discusión supuso importantes debates en los equipos de investigación y de extensión universitaria que aplicaron a las convocatorias mencionadas.

Así fue como nos involucramos en importantes innovaciones metodológicas donde la antropología tuvo mucho que decir, en especial a partir de las reflexiones asociadas al enfoque etnográfico que le es característico.

De esta manera, se vienen formulando planteos alternativos que priorizan trabajos de tipo "colaborativo" y se articulan con diversos sujetos sociales e instituciones. Por eso, no investigamos o trabajamos "sobre" determinada población o grupo, sino "con" ellos (MATO, 2014; BARTOLOMÉ, 2004a), en forma articulada y mancomunada. Además, las producciones ya no están dirigidas exclusivamente al ambiente antropológico y/o de las ciencias sociales, ya que, como ha destacado acertadamente Bartolomé (2004a, p. 74) "es cada vez más frecuente que los otros se nieguen a ser representados por nosotros". Se trata de no desatender o naturalizar en forma acrítica la suposición metodológica mediante la cual "construimos un objeto de investigación" (BOURDIEU; WAIQCUANT, 2008). Por el contrario, consideramos que el proceso de conocimiento es dialéctico en la relación entre el investigador y los diferentes sujetos. Por ende, el trabajo etnográfico es producto de un 
contexto compartido y de la elaboración del conocimiento en conjunto. Como señalamos en otra oportunidad, las labores de extensión, la investigación con transferencia, etc., nos abren caminos a través de nuevos interrogantes que no surgen exclusivamente desde el investigador, sino a partir de la relación con los sujetos (RUGGIERO et al, 2016). En definitiva, estas fórmulas innovadoras posibilitan un aporte en conjunto donde las transformaciones son continuas, la devolución es un proceso de enriquecimiento compartido $y$, además, se promueve la transformación desde el diálogo permanente como expresión y objetivo de la etnografía (BARTOLOMÉ, 2004a).

Como resultado de la creciente presencia de diversas organizaciones sociales, políticas y sindicales -entre ellas, las organizaciones indígenas - y las repercusiones y articulaciones que se vienen generando en el conjunto de la sociedad en las últimas décadas y, en especial, en los últimos años, algunos sectores sociales vienen efectuando una profunda crítica y revisión a la historiografía tradicional (y a sus diversas versiones en ámbitos regionales y locales). Además, a la historiografía tradicional se le atribuye haber sido parte sustancial de la invisibilización y estigmatización de los pueblos originarios a lo largo de la historia e, incluso, de ser cómplice del "etnocidio" y el "genocidio" perpetrados.

Un aspecto fundamental de las visiones alternativas en historia, antropología, sociología y las restantes ciencias sociales, implica la recuperación de la memoria oral de estos pueblos. En la mayor parte de los casos, actualmente, por primera vez, se ha registrado y plasmado en publicaciones (libros, audiovisuales, revistas, cartillas, folletos, etc.).

En relación a estos cambios, ha sido sustancial, a partir del devenir democrático, la consolidación de lecturas sumamente críticas a la 
historiografía y la antropología tradicional, y el desarrollo de diferentes equipos de profesionales que incorporen a las nuevas generaciones de investigadores jóvenes. Así, se fortalecieron líneas de investigación que, por un lado, refutaron y derribaron muchos "mitos" construidos por las lecturas tradicionales $\mathrm{y}$, por otro, plantearon, precisamente, una construcción de conocimiento conjunta.

En definitiva, así como hay una historiografía tradicional que ha "conversado" con el ideario positivista y conservador que negó a los pueblos originarios, las perspectivas críticas en ciencias sociales y humanas que han ganado presencia actualmente y sobre las que hay amplio consenso en las diferentes disciplinas, mantienen un estrecho vínculo con organizaciones sociales, algunos ámbitos del Estado y con los propios pueblos indígenas.

Un hito en relación con estas dinámicas se dio a partir de los "contrafestejos" por la conmemoración del V Centenario del Descubrimiento de América, en $1992^{29}$. Como nos expresaron dirigentes indígenas, fue por aquel entonces "cuando llegamos a la universidad" ${ }^{30}$ y ahí "se armó todo un trabajo, y desde ahí salieron después otra gente [en relación a diversos profesionales] como teniendo otra visión". Así se han empezado a conocer padecimientos, despojos y reivindicaciones de los pueblos originarios a lo largo del siglo XX, y comenzaron a difundirse aportes que recuperan estas vivencias tradicionalmente invisibilizadas.

Desde nuestro equipo, en estos años hemos desarrollado diversos

29 La conmemoración de los 500 años del denominado "Descubrimiento de América" significó una oportunidad en toda América Latina para que los diferentes pueblos se organizaran, plantearan sus demandas ante el conjunto de la sociedad y se mostrara la continuidad entre los pueblos prehispánicos y los actuales. Paradójicamente, en muchos contextos de la región, los "contrafestejos" ocuparon un lugar más significativo que los "festejos" oficiales (organizados por Estados e instituciones hispanas). Estos fueron un hito que hizo posible visibilizar las demandas indígenas y repudiar el proceso de colonización (BENGOA, 2007).

30 Expresiones vertidas por un dirigente indígena en un panel en la Facultad de Filosofía y Letras de la Universidad de Buenos Aires. 
proyectos de trabajo colaborativo con diferentes organizaciones de los Mapuche y otros pobladores y obtuvimos resultados. Los hemos desarrollado tanto con organismos públicos, como el Instituto Nacional de Asuntos Indígenas ${ }^{31}$, como a partir de proyectos financiados por el Ministerio de Educación (como los de Voluntariado Universitario). Algunos de los resultados recabados son los que se adjuntan en los siguientes apartados ${ }^{32}$. En muchos lugares del país, diferentes equipos universitarios replicaron trabajos comparables con los pueblos indígenas junto con diversas organizaciones sociales ${ }^{33}$.

\author{
Finalmente, cabe señalar que el trabajo articulado con \\ organizaciones sociales locales nos permitió complejizar la relación entre
} los Mapuche y una categoría social muy extendida en la zona: la de

\begin{abstract}
31 En 2003, a partir del trabajo de investigación que desarrollamos en Norpatagonia, algunos miembros del equipo iniciamos un trabajo conjunto de transferencia y apoyo a los pobladores Mapuche de la localidad de Villa La Angostura (departamento Los Lagos, provincia de Neuquén). Efectuamos un estudio, a pedido del Instituto Nacional de Asuntos Indígenas (INAI), basado en la recopilación de historias de vida y fuentes documentales de los pobladores Paichil Antriao y Quintriqueo, que reclaman su reconocimiento como comunidad mapuche. El proyecto finalizó con la publicación de un libro (Historia de las familias Mapuche Lof Paichil Antriao y Lof Quintriqueo de la Costa Norte del Nahuel Huapi) compilado por la Biblioteca Popular, en el cual docentes y estudiantes del grupo escribimos tres artículos - junto con profesionales de otras universidades-. Estos artículos reflexionan acerca de la problemática mapuche y recopilan las historias de vida de los pobladores. Este estudio fue clave para que obtuvieran la personería como comunidades ante el INAI, que se concretó en 2007.

32 Entre 2006 y 2009, trabajamos en diferentes proyectos de Voluntariado Universitario centrados en la recuperación de los testimonios de los pobladores de la zona de Villa Traful y áreas aledañas, que concluyeron en las siguientes publicaciones: Relatos Patagónicos. Historias familiares en la construcción del espacio social en Villa Traful, de Sebastián Valverde, Analía García y Lara Bersten (editores), publicado en 2008 (VALVERDE et al. 2008) por Ferreyra Editor, en Córdoba, Argentina. También en la obra (continuación de la anterior) El territorio en perspectiva. Política pública y memoria social en Villa Traful, de Analía García y Lara Bersten (compiladoras), se editó en Buenos Aires y es una edición de autor (GARCÍA; BERSTEIN, 2009). En la convocatoria 2010 del proyecto de Voluntariado Universitario, efectuamos un análisis entre comunidades mapuche de la provincia de Río Negro. El resultado es la obra, Volver al Territorio. Memorias Mapuches en el Parque Nacional Nahuel Huapí, de Sebastián Valverde, Florencia Trentini, Alejandra Pérez y Gerardo Ghioldi (este último de la Biblioteca Popular "Osvaldo Bayer"), editado por la Facultad de Filosofía y Letras de la Universidad de Buenos Aires en 2013 (VALVERDE et al., 2013).

33 Un ejemplo de estos trabajos desarrollados en forma conjunta entre la universidad y las organizaciones indígenas es el compilado - a partir de testimonios orales y diferentes documentos- por Elena Belli, Ricardo Slavutsky y Pantaleón Rueda acerca del denominado "Malón de la Paz". Esta fue una emblemática movilización indígena de las comunidades de la región de la Puna (provincia de Jujuy), que en 1946 se trasladaron hacia la Ciudad de Buenos Aires para entrevistarse con el entonces presidente de la Nación, Juan D. Perón, y reclamar por la devolución de las tierras que habían pertenecido ancestralmente a estos pueblos indígenas y en ese momento estaban usurpadas (BELLI et al, 2007).
\end{abstract}


"pobladores", que funciona como una auténtica "categoría social"34.

Esta denominación englobadora de "pobladores" fue definida desde las políticas estatales e internalizada por los propios sujetos como forma de designarse a sí mismos y a otros. Se refiere a que es "oriundo" del lugar. También remite a una idea de que es pequeño productor. Esta categoría representa un universo sumamente heterogéneo que, en algunos casos, posee una raíz cultural común con los indígenas (no así en otros que son de origen criollo o, en menor medida, europeo, pero al ser de escasos recursos quedan incluidos en este grupo).

Así, observamos que existen características comunes entre los "indígenas" y los "pobladores". Entre ellas, podemos mencionar el hecho de que basan su subsistencia en una economía familiar, con trabajos asalariados muy precarios. También representa un punto en común la identidad respecto de la región, la construcción de la frontera y la relación con las zonas trascordilleranas cercanas, que luego pasarían a formar parte de Chile (VALVERDE et al, 2008; GARCíA et al, 2008).

A partir del trabajo articulado con diversas organizaciones sociales en la región, observamos cómo diversas identidades se contraponían, en algunos casos, y, en otros, se interpenetraban y superponían. Tal es el caso de identidades muy arraigadas en algunas de estas zonas, como la de "primeros pobladores" o "pobladores". En definitiva, observamos cómo la conformación del Estado-Nación implicó la construcción de esta adscripción que, en ciertas coyunturas específicas -como la llegada de las primeras instituciones-, sustituyó a otras. En otras palabras, la homogeneización fue uno de los mecanismos que utilizó la joven

\footnotetext{
34 Retomamos la definición de "categoría social" de Elsie Rockwell, quién señala: "Por categorías sociales entiendo aquellas representaciones o prácticas que aparecen de manera recurrente en el discurso o en las acciones de los habitantes locales y que establecen distinciones entre cosas del mundo que ellos conocen y manejan" (2009, p. 80).
} 
estructura burocrática, dinámica que implicó la estigmatización deliberada de ciertas identidades (como "chilenos"; "indígenas", etc.) (GARCÍA et al, 2008; VALVERDE et al, 2008). En efecto, muchos de los "pobladores", tienen un origen mapuche, pero han padecido históricamente una discriminación que los ha llevado a emplear esta categoría tan extendida y legitimada en la zona.

\section{Los pueblos indígenas en el período de las dictaduras cívico-militares $^{35}$}

Uno de los aspectos que vamos a abordar en este apartado tiene que ver con los desalojos que sucedieron en las décadas de 1950, 1960 y 1970 -en especial, en los períodos de las dictaduras cívico-militares de 1955-1958, 1962-1963, 1966-1973 y 1976-1983- principalmente, en la zona que corresponde a la jurisdicción de Parques Nacionales.

Recordemos que, desde su fundación en 1934, Parques Nacionales ha ejercido un rol clave en el desarrollo regional, ya que se transformó en el principal referente del Estado sobre el territorio, de allí la acertada caracterización de Navarro Floria (2008) como un "Estado-Parque". Responsable del aprovisionamiento de infraestructura básica (por ejemplo, de edificios públicos y privados), loteó tierras, asignó autorizaciones para la instalación de pobladores y fijó los controles para el conjunto de los recursos (cotos de caza, talas de árboles, extracción de leña, etc.) (VALVERDE, 2006; GARCÍA et al, 2008). Parques Nacionales ha

35 Al referirnos a las dictaduras cívico-militares, aludimos a los períodos de ruptura del orden constitucional que se dieron en la Argentina entre 1955-1958, 1962-1963, 1966-1973 y 1976-1983. Consideramos estos períodos de la segunda mitad del siglo XX debido al mayor nivel de represión y conflictividad en comparación con años anteriores, y dado que están aún presentes en la memoria de los pobladores indígenas. 
aplicado, a lo largo de la historia, una política sumamente expulsiva y restrictiva hacia los pobladores indígenas y criollos de escasos recursos, al tiempo que favoreció a los "pioneros" (de origen europeo), hecho explicable a partir de la impronta conservadora, nacionalista y sumamente elitista de sus medidas.

La segunda mitad de la década de 1950 y, en especial, la de 1960, se caracterizan por un creciente nivel de conflictividad de los pobladores indígenas y criollos (de escasos recursos) con esta institución y con las grandes estancias, hecho que se puede verificar tanto a partir del recuerdo oral de los pobladores, como de diversos documentos -en los cuales muchos habitantes originarios empiezan a ser considerados "intrusos"-.

Cabe señalar que, al asentarse en la región cordillerana, las áreas de Parques Nacionales son las más valoradas, ya que cuentan con lagos, montañas y atractivos paisajes. A la vez, durante las décadas de 1950 y 1960 se acrecentó la presencia (y la presión) de diversos agentes privados con intereses ligados a la explotación turística e inmobiliaria, lo que explica estos crecientes conflictos.

A partir de aquel momento, la política fue de hostigamiento hacia los pobladores de escasos recursos (chilenos, descendientes de indígenas, con ascendencia criolla e indígena, etc.) que se asentaban en la jurisdicción del Parque Nacional Nahuel Huapi. Esta tendencia se dio desde fines de la década de 1950, pero se profundizó en la segunda mitad de la década de 1960 (especialmente, en el período de la dictadura militar presidida por el General Juan Carlos Onganía). Aquellos años, el accionar de Parques Nacionales con los pobladores fue particularmente represivo, sobre todo a partir de la gestión del intendente Raúl Sosa.

En estos desalojos, se han dado situaciones sumamente dramáticas, 
e incluso la muerte de algunos pobladores, que recién en los últimos años salieron a la luz, a partir del accionar de diversas organizaciones indígenas y sociales, la recuperación de la oralidad y la memoria, y la articulación con otros sectores sociales (entre ellos, los ámbitos universitarios).

Recordemos la historia de la familia Tacul —quienes, actualmente, conforman la comunidad Takul Cheuque- con que iniciamos este artículo. Una de las pobladoras que entrevistamos - de muy avanzada edad $^{36}$ - comenta las situaciones que padecieron en aquella época:

Parques mandó dos camiones y nos subieron todas las cosas arriba y como si fuéramos un palo de leña, nos vinieron a tirar acá en Bariloche. Nos prometían un terreno grande, pero era mentira, después dijeron que nos iban a llevar a la quinta $n^{\circ} 26$, ahí no había nada, era una quinta grande, unas dos cuadras, más o menos, y ahí nos dejaron un par de tablas para que levantemos, nos tiraron las cosas ahí afuera y arreglate como puedas (VALVERDE et al, 2013).

En efecto, tal como cuenta la pobladora Tacul (que había vivido de joven en el territorio), luego les prometieron un terreno (en lo que hoy es la zona urbana de San Carlos Bariloche, a unos $4 \mathrm{~km}$ del centro de la ciudad), pero luego los volvieron a desalojar de allí. Por eso, migraron a Clemente Onelli (a unos $110 \mathrm{~km}$ de Bariloche) ${ }^{37}$, donde tenían familiares que los ayudaron en esta difícil coyuntura. Finalmente, se trasladaron a los barrios populares de Bariloche, donde se establecieron y residen hasta la actualidad.

Los testimonios de esta familia evidencian cómo, a lo largo de

36 Fallecida en 2013.

37 Ver el libro Volver al territorio. Memorias Mapuches en el Parque Nacional Nahuel Huapi (VALVERDE et al, 2013), resultado del proyecto de voluntariado universitario 2010-2011, donde analizamos en detalle la historia de esta comunidad. 
décadas, las diferentes generaciones reviven estos hechos. Pero también se observa cómo en períodos de represión e inhibición del ejercicio de sus derechos se trasmiten experiencias que serán clave para dar lugar a procesos organizativos y movilizaciones posteriores. En palabras de las dirigentes actuales de la comunidad (nietas de Ismael Tacul que se criaron en las duras condiciones de migración forzada a Bariloche): “...con mi mamá siempre hablábamos, decíamos pero cómo, cómo puede ser que ustedes no hayan podido hacer nada. Decía, yo decía, si yo en ese momento hubiera estado yo lo peleo".

No obstante, la misma entrevistada reconoce la diferencia entre aquel momento y el actual, al manifestar, en el mismo pasaje:

pero yo no me daba cuenta de que también, ellos eran jóvenes en el momento que los echaron pero no estaban las condiciones, no se daban las condiciones de decir bueno, yo me agarro de esta ley, con esta ley no me van a echar. No, ahí era totalmente al revés.

Allí mencionan también lo que había sido el período de dictaduras y el avance de agentes privados en ese contexto: "nos agarró todo el proceso militar, habían loteado todo para vender ahí, y durante el proceso militar no podías hacer nada, te metían preso, y más siendo indígenas". Luego, retomaremos este aspecto para conceptualizar la memoria y la identidad como Mapuche y los conflictos más recientes.

Otro ejemplo son los hechos que ha padecido la familia Melo, en el paraje El Pedregoso, en la costa norte del lago Nahuel Huapi, a mitad de camino entre San Carlos de Bariloche y Villa la Angostura. El jefe de familia, Marcos Melo, nació en la región de Cura Cautín, Chile, de donde emigró en 1912, para radicarse al este de la cordillera (donde luego se consolidaría el Estado argentino $)^{38}$. 
Los Melo eran "puesteros" en la zona desde fines de la década de 1920 (es decir, con anterioridad a la constitución del Parque Nacional Nahuel Huapi). Allí se dedicaban a la cría de ganado y la agricultura familiar en huertas. Marcos Melo, jefe de la familia, habitó el paraje junto con su esposa y sus nueve hijos, que se criaron y vivieron en el lote $n .^{0} 42$ de El Pedregoso (La Angostura Digital, 27/12/11) ). $^{39}$

En 1966, un momento muy complejo para los pobladores del Parque Nacional Nahuel Huapi (ya que la presión sobre ellos aumentaba día a día), Parques Nacionales notificó y luego efectivizó el desalojo de los Melo. Unos días después, ocurrió un hecho trágico: Marcos Melo apareció ahorcado en el territorio donde había residido siempre: el puesto "Melo". De acuerdo con los testimonios recabados, a partir del desalojo, la familia tomó diferentes rumbos. Un grupo se quedó viviendo en la localidad de Villa la Angostura; otros - en palabras de los nietos de Marcos Melo- "se fueron a Bariloche, a Mar del Plata, otros a Chile, en realidad se perdieron. No volvieron, no quisieron volver nunca más".

Un aspecto a remarcar es el miedo y la autocensura a partir de las experiencias traumáticas por las que han atravesado. Como señala uno de los nietos de Melo:

El otro día vino la prima de mi papá que se crió acá [en relación al puesto Melo], que en realidad ella tampoco quería saber nada de volver acá, porque dice que tiene muy malas experiencias de esto, de haber vivido acá, de

-y de hecho faltaban varias décadas para la efectivización de la cordillera de los Andes como un "límite"tal como vienen destacando diferentes estudios históricos (BANDIERI, 2005; MÉNDEZ, 2006; 2010). 39 Una prueba muy destacada del asentamiento de la familia Melo, es la "Carta Topográfica de la República Argentina" (1947) correspondiente a la Hoja No 4172-16 denominada "Paso Coihue", elaborada por el Ejército Argentino - Instituto Geográfico Militar, a partir de relevamientos efectuados por aquellos años. Este documento representa un testimonio fundamental, ya que uno de los puestos, -es decir de los pobladores asentados al momento de efectuarse este relevamiento- es precisamente el "puesto Melo" en el actual área de asentamiento de esta población, en la zona "del Pedregoso".

A la vez, hemos podido recabar diferentes constancias de comercialización de animales por parte de Melo -muchas certificadas por el Juez de Paz-, con vecinos de la zona, en diferentes años, lo cual es una prueba contundente de la realización de estas actividades como rianceros y su continuidad en el tiempo. 
haberse quedado huérfano, y después de que inclusive haya muerto el abuelo que los crió a ellos.

Otro caso al que haremos referencia tuvo lugar en una zona del Parque Nacional Nahuel Huapi donde se produjo una gran cantidad de desalojos en las décadas de 1960 y 1970: la localidad de Villa Traful ${ }^{40}$. En 1977 -en plena dictadura cívico-militar-, se produjo el desalojo de la familia Iturra (Francisco Iturra ${ }^{41}$, su esposa y sus siete hijos) del paraje Paloma Araucana, muy cercano a Villa Traful. Este hecho trajo aparejada la muerte de una de las niñas, como consecuencia de las paupérrimas condiciones en que vivieron luego de ser desalojados, ya que debieron pasar el invierno patagónico ${ }^{42}$ en una vivienda muy rudimentaria.

En 2007 -en el marco de un proyecto de voluntariado universitario de recuperación de la memoria de los pobladores-, entrevistamos a la hermana melliza de la niña fallecida y comprobamos lo traumático de los hechos acaecidos 30 años antes. La entrevista fue sumamente difícil. En primer lugar, la mujer se negaba a dar su testimonio (frente a la desconfianza y estigmatización de las que suele ser objeto) y, luego, al relatar una y otra vez los dramáticos hechos. Concluimos que aquellos acontecimientos generaron fragmentación social y enfrentamientos entre las familias (incluso, hasta el día de hoy).

\section{Expulsión forzada, memoria y trayectorias}

Por motivos de espacio, no ahondaremos en otros ejemplos, pero

40 Se trata de otra de las villas turísticas fundadas por Parques Nacionales en la década de 1930 para poblar una de sus áreas. Esta institución permitió el loteo de terrenos en un área del parque.

41 Francisco Iturra se casó Hermelinda Calfueque, una de las familias mapuche de la zona.

42 En los meses de invierno, en localidades de la región cordillerana como Villa Traful, la temperatura es cercana a los cero grados centígrados $\left(0^{\circ} \mathrm{C}\right)$, con precipitaciones en forma de lluvia y nieve, heladas, fuertes vientos, etcétera. 
podemos mencionar, brevemente, casos comparables. Un ejemplo es la comunidad Maliqueo ${ }^{43}$ en la zona de Bariloche (en la década de 1950), o los Cayun de la zona de "el Machete" (ARCHIVOS DEL SUR, 2013) a quienes intentaron desalojar en la década de 1990, aunque finalmente no se concretó.

Lo mismo podemos decir de la comunidad mapuche Ñorquinco ${ }^{44}$, en el Parque Nacional Lanín (vecino del Parque Nacional Nahuel Huapi). De hecho, diversos desalojos han tenido una importancia central como "cisma", y han generado cambios dentro de la institución y en la relación con los pobladores. A fines de la década de 1990, ya en plena democracia y luego de haber afianzado los derechos de los pueblos indígenas - junto con otros sectores sociales que han funcionado como aliados-, se intentó concretar un desalojo en el Parque Nacional Lanín, pero los resultados fueron muy diferentes ${ }^{45}$.

En relación con las dinámicas que aquí describimos, existe una tendencia histórica de subordinación de ciertos colectivos sociales. Se

\footnotetext{
43 Ver el trabajo que publicamos en que abordamos la historia de la comunidad Maliqueo al igual que Tacul (VALVERDE et al., 2013).

44 Hasta la década de 1940, residía un destacado grupo de familias mapuche sobre la costa del lago Ñorquinco, en el extremo norte del Parque Nacional Lanín (en el Departamento Aluminé de Neuquén) articulados en torno al lonko Aniceto Catrileo. A de esa década, luego de la conformación del mencionado parque (que tuvo lugar en 1937), estas familias fueron expulsadas y reasentadas unos kilómetros al este, en las adyacencias de la estancia Pulmarí.

45 De hecho, hace algo más de una década, en 1999 -momento muy diferente en términos político-institucionales y en cuanto a la presencia y organización de diferentes actores sociales que en las décadas de 1950, 1960 y 1970 - la conducción del Parque Nacional Lanín intentó desalojar a la familia mapuche Quilapán (asentada en el lago Huechulafquen) y se produjo una inédita e inesperada movilización de organizaciones y comunidades indígenas, junto con trabajadores del Parque Nacional (nucleados en su sindicato, la Asociación de Trabajadores del Estado). Las acciones desarrolladas, que implicaron la toma de la Intendencia del parque, movilizaciones, diversas declaraciones públicas, etc., no solo detuvieron el intento de desalojo, sino que, como consecuencia, cambiaron las autoridades y las políticas institucionales del parque en relación con los pobladores ancestrales. Esta movilización coincidió, además, con el cambio de Gobierno nacional (finalizaba la presidencia de Carlos Menem) y con el recambio en las autoridades de la Administración de Parques Nacionales (dependiente del Estado nacional). Como resultado de dicha movilización, se inició el denominado "co-manejo" del Parque Nacional Lanín, que implicó una administración conjunta de los territorios entre esta institución, las comunidades mapuche y la Confederación Mapuche Neuquina (organización etnicista que nuclea a las comunidades y los pobladores urbanos). Así, se reconoció a los Mapuche no solo como interlocutores válidos, sino como activos partícipes en el proceso de conservación de esta área protegida (CARPINETTI, 2005; VALVERDE, 2013).
} 
trata de la internalización —en los propios pobladores indígenas, al igual que en criollos en situación de pobreza, migrantes, etc.- de los atributos estigmatizantes que diferentes sectores de la sociedad les aplican. Esto produce una actitud de autocensura en relación con las vivencias padecidas, sobre todo, en contextos de expulsión forzada y, particularmente, en el caso de la población indígena, ante la desvalorización cultural que estos procesos conllevan. Miguel Bartolomé ha señalado:

En los lugares de relocalización [en relación a los procesos de expulsión forzada de población indígena] no sólo se desarrollan nuevos tipos de sistemas interétnicos, sino que en éstos la posición indígena tiende a ser aún más subordinada como consecuencia -entre otros factores- de la autoimagen devaluada que resulta del desplazamiento (1992, p. 26).

Ahora bien, no son pocos - o están cada vez más extendidos - los casos de poblaciones que han mantenido en silencio -incluso, en el ámbito más íntimo del recuerdo estrictamente individual- las vivencias de despojo, a pesar de los efectos perjudiciales que padecieron.

Sin embargo, en las últimas décadas, estos hechos comenzaron a hacerse públicos, lo que implica la creciente recuperación de relatos y saberes de los integrantes de los pueblos indígenas y de los denominados "pobladores". Esto resulta indisociable de la revalorización étnico-identitaria de los pueblos indígenas -como los Mapuche-, asociada al reconocimiento social y político-jurídico en que se enmarcan estos procesos.

\section{Reflexiones finales, cierres a modo de aperturas}


A lo largo de este artículo, nos propusimos profundizar en diversos aspectos que involucran al pueblo Mapuche -en particular, en la región del Parque Nacional Nahuel Huapi donde desarrollamos nuestro trabajodurante las décadas de 1950, 1960 y 1970. Como ya hemos señalado, los dramáticos hechos que tuvieron lugar en las dictaduras-cívico militares han sido largamente abordados por variados sectores, organizaciones sociales, el Estado y, desde ya, los ámbitos académicos. Esto da cuenta de la gravedad que tuvieron estos hechos en la historia argentina reciente.

A la vez, la fuerza que han tenido (y tienen) las organizaciones de Derechos Humanos - como Madres y Abuelas de Plaza de Mayo, un símbolo a nivel mundial- ha contribuido a la revisión de lo que fueron esos oscuros años, así como al juzgamiento de los genocidas del período 1976-1983. Sin embargo, una situación particular se plantea con los pueblos indígenas: paradójicamente, la suerte de estos en los períodos de dictaduras cívico-militares es una temática que, como hemos visto, ha sido escasamente tratada.

Esto nos lleva a atender diversas cuestiones. Por un lado, la conflictividad territorial, las estigmatizaciones y atributos desacreditantes que se les atribuyen a estos pueblos. Por otro, - aunque asociado- el arraigo histórico de las poblaciones y comunidades en directa vinculación con las distintas reivindicaciones.

Precisamente, en pos de comprender los conflictos territoriales que se vienen registrando en la actualidad, debemos tener en cuenta que una de sus aristas fundamentales se vincula con la recuperación de las vivencias por las que han atravesado estos pueblos, que hasta hace pocos años estuvieron ocultas y restringidas al ámbito familiar (e, incluso, a la esfera estrictamente individual). 
En tiempos recientes, en un contexto muy diferente, estas situaciones se empiezan a revertir y comienzan a conocerse los hechos traumáticos. A la vez, emerge y se expande la demanda por justicia y reparaciones frente a las arbitrariedades históricas.

En el caso de la comunidad Takul Cheuque, hemos dado cuenta de la revalorización, por parte de las nuevas generaciones, de los sucesos que tuvieron lugar en el pasado. También vimos de qué manera el retorno de la democracia implicó el creciente ejercicio de derechos como parte de un pueblo originario, lo que conllevó una recuperación de los territorios ancestrales de Villa Tacul.

Lo mismo podemos decir del caso de los hermanos Melo (nietos de Marcos Melo), quienes, desde 2011 , efectúan un reclamo por el territorio del paraje en El Pedregoso (el puesto "Melo"), donde había vivido su abuelo y se suicidó tiempo después de ser desalojado.

Antes, señalábamos la importancia que esta recuperación de las vivencias tiene en pos de visibilizar el arraigo histórico de estas poblaciones y comunidades. Un argumento muy extendido para deslegitimar el reclamo de los pueblos indígenas y, en particular, del pueblo Mapuche, consiste en cuestionar las demandas actuales, y preguntarse, en forma suspicaz, por qué esos reclamos "no se hicieron antes”. Un ejemplo emblemático es del lonko José Mercedes Quintriqueo, quien como poblador del Parque Nacional Nahuel Huapi durante décadas demandó al Estado (antes de que esta familia se reorganizara en la comunidad Lof Kinkikew) por los territorios que ocupa ancestralmente, cuando intentaron desalojarlos en varias oportunidades. Esto nos permite concluir que el reclamo actual de la comunidad Lof Kinkikew lejos está de ser reciente o "interesado"; posee varias décadas de antigüedad. Más aun, José Mercedes Quintriqueo efectuó reclamos a los directivos de Parques 
Nacionales en las décadas de 1960 y 1970, y a las máximas autoridades nacionales, como el General Juan Carlos Onganía (además de otros presidentes en períodos democráticos, como Arturo Frondizi o Umberto Illia) en contextos sumamente difíciles del país.

Que todos estos hechos que describimos salgan a la luz (como los que padecieron los Melo, los Iturra, los Tacul, los Maliqueo, los Catrileo, los Calfinahuel, los Reyes, los Quintriqueo, etc.) es el resultado de cambios en el propio reconocimiento y en una afirmación de larga data como sujetos sociales y políticos (ITURRALDE, 1991).

Para explicar estas transformaciones, debemos comprender cómo estos procesos han llevado décadas de reafirmación democrática, durante las cuales surgieron y se consolidaron diversas organizaciones sociales, políticas y sindicales, y se produjo una redefinición en el vínculo de indígenas y pobladores con organismos y ámbitos estatales -entre ellos, universitarios- y no estatales (iglesias, ONG) ${ }^{46}$.

Sin embargo, esta recuperación de vivencias no se reduce a "escribir" sobre ellas (lo cual, de por sí, no es poca cosa). Implica una profunda transformación en los pueblos indígenas como sujetos sociales, que produjo que muchas de sus experiencias de despojos, o bien sus propias versiones del pasado - como expresa Tozzini- sean "por primera vez en la historia, posibles de ser narradas" (2008, p. 2). Este proceso se asocia con el progresivo autorreconocimiento de los pueblos y la revalorización de las trayectorias por las que han atravesado y hoy pueden ser compartidas - por ellos mismos-de forma muy diferente a lo que sucedía tiempo atrás.

En este sentido, debemos considerar la trascendencia que adquiere

46 Una muestra de ello es que uno de los nietos de Marcos Melo, Lucas Melo, tiene una destacada participación política local e, incluso, ha sido concejal de la localidad de Villa la Angostura, durante el período 2015-2017. 
la memoria grupal, al ser "el gran nutriente de la identidad", ya que -según Candeau-, "las identidades colectivas remiten a una problemática de las "raíces" o de los orígenes, que viene asociada invariablemente a la idea de una memoria o de una tradición" (GIMÉNEZ, 2009 , p. 20). De allí la importancia que adquieren los "actos de recordar" en la elaboración de la identidad del grupo de más larga data, así como en los ligados a las luchas más recientes.

Otro elemento que juega un papel fundamental en estos procesos es la revalorización de la propia imagen devaluada (que empieza a revertirse), la "redefinición o reestructuración de las experiencias previas", tal como ha destacado Bartolomé (2004b, p. 98).

Esa memoria, en relación con estos hechos, y cómo se redefine en el presente es parte fundamental de la identidad del grupo. La identidad específica del grupo en cuestión (sean comunidades, familias, población), su fortalecimiento como tal y como se estructuran las relaciones con los diferentes "otros" constituyen aspectos fundamentales de esta reafirmación identitaria.

En estas dinámicas, han incidido profundamente las luchas culturales y políticas que protagonizaron durante las últimas décadas, en las que fue clave el papel de las nuevas organizaciones etnopolíticas. A la vez, tal como señalábamos al principio del trabajo, ha sido clave el rol de diferentes proyectos y del trabajo colaborativo de los pobladores y las organizaciones y comunidades indígenas con ámbitos académicos, instituciones y organizaciones sociales, políticas y sindicales, en pos de contar esta "otra historia" de la cual poco se sabe en la "historia oficial de la región".

Para finalizar, enfatizamos el rol que han tenido las políticas públicas el período 2003-2015 en relación con el fortalecimiento de la 
universidad y en la articulación con variados sujetos sociales, entre muchos otros, los pueblos indígenas. El desarrollo de diversas metodologías de trabajo innovadoras en ámbitos académicos y el fortalecimiento de la propia concepción de investigadores comprometidos con la realidad vienen desarrollándose hace años y generan destacados resultados.

Además, lo dicho cobra importancia dado el creciente nivel de conflictividad y estigmatización hacia los pueblos indígenas, en general, y hacia el pueblo Mapuche, en particular, que se vive desde 2017, como resultado de la restauración conservadora y el giro hacia políticas neoliberales ${ }^{47}$. Por eso, remarcamos la trascendencia que tiene el trabajo articulado y colaborativo con pueblos indígenas en contextos como el presente, que tiene muchos puntos en común con otros períodos "oscuros" de nuestra historia.

Por último, hacemos llegar nuestro sentido homenaje a diferentes pobladores del Parque Nacional Nahuel Huapi, victimas de la represión y el terrorismo de Estado, que hoy están ausentes. A Mariana Iturra y Marcos Melo. A Francisco Iturra, que no pudo soportar tanta injusticia y tanto dolor. A Fresia Tacul y Adrián Melo, que se fueron en estos años de reafirmación de las comunidades y sus derechos. A las victimas recientes en tiempos tan complejos: Rafael Nahuel y Santiago Maldonado. Y a

\footnotetext{
47 Un contexto novedoso se planteó desde de mediados del 2017 en relación con los pueblos indígenas, donde los mismos han adquirido una presencia mediática inusitada en estrecha relación con un hecho que conmocionó al país: la desaparición -y luego confirmación de la muerte- del militante Santiago Maldonado en un escenario signado por la represión por parte de la Gendarmería Nacional (fuerzas de seguridad) a la comunidad del pueblo indígena Mapuche "Pu Lof en Resistencia" de Cushamen, en la provincia de Chubut, en el sur del país. Con el correr de los meses, la situación se fue agravando a raíz de la instalación y embestida de discursos estigmatizantes, una creciente criminalización y judicialización hacia las comunidades étnicas, en general, y hacia el pueblo Mapuche, en particular. A esto debemos sumarle la escalada de acciones violentas hacia diferentes comunidades indígenas del país, tales como los allanamientos en Campo Maripe (ubicado en la zona petrolera de la provincia del Neuquén), la quema de viviendas de indígenas por parte de fuerzas parapoliciales en la zona del conflicto en la provincia de Chubut (ARANDA, 2018), o finalmente, el asesinato del militante mapuche Rafael Nahuel, en una zona cercana a Bariloche, entre otros acontecimientos.
} 
tantos más...la lista no deja de ser arbitraria e incompleta. Por todos ellos, debemos redoblar nuestro compromiso en consolidar una antropología crítica, inserta en la realidad. Por ellos, memoria verdad y justicia.

\section{Bibliografía}

ALONSO, L. Prólogo al Informe de Gestión de la Subsecretaria de Coordinación de Políticas Universitarias. Ministerio de Educación de Argentina, 2015.

BALAZOTE, A. O. Pueblos Originarios: disputas en el campo discursivo. Revista GeoPantanal, v. 10, n. 18, p. 33-50, 2015.

BALAZOTE, A.; RADOVICH, J. C. El tratamiento de la cuestión indígena en Marcelo Bórmida. Trabajo presentado en las VI Jornadas de investigación en Antropología Social. Buenos Aires: Instituto de Ciencias Antropológicas, Facultad de Filosofía y Letras, Universidad de Buenos Aires, 2010.

BARTOLOMÉ, M. A. Los pobladores del "Desierto" genocidio, etnocidio y etnogénesis en la Argentina. Cuadernos de Antropología Social, Buenos Aires, n. 17, p. 162-189, 2003.

. En defensa de la etnografía: el papel contemporáneo de la investigación intercultural. Avá, Misiones, n. 5, p. 69-89, 2004a.

Movilizaciones étnicas y crítica civilizatoria: un cuestionamiento a los proyectos estatales en América Latina. Perfiles Latinoamericanos, Ciudad de Mexico, v. 12 , n. 24 , p. $85-105,2004$ b.

Interculturalidad y territorialidades confrontadas en América Latina. Runa, Buenos Aires, v. 31, n. 1, p. 9-29, 2010.

BARTOLOMÉ, M.; RADOVICH, J. C. Apuntes para la memoria: Miguel Hángel González una figura casi olvidada de la antropología argentina. Relaciones de la Sociedad Argentina de Antropología, v. 39, n. 1, p. 233-244, 2014.

BELLI, E.; SLAVUTSKY, R.; RUEDA, P. Malón de la Paz: "una historia, un camino". Tilcara, Jujuy: Instituto Interdisciplinario de Tilcara, Facultad de Filosofía y Letras, Universidad de Buenos Aires, 2007. 
BENGOA, J. La emergencia indígena en América Latina. Santiago de Chile: Fondo de Cultura Económica, 2007.

BOURDIEU, P.; WACQUANT, L. Una invitación a la sociología reflexiva. Buenos Aires: Siglo XXI, 2008.

BUNGE, M. Ciencia, técnica y desarrollo. Buenos Aires: Siglo XXI, 1984.

CARPINETTI, B. Derechos indígenas en el Parque Nacional Lanín: de la expulsión al comanejo. Buenos Aires: Administración de Parques Nacionales, 2005.

GARCÍA, A.; BERSTEN, L. (Org.). El territorio en perspectiva: política pública y memoria social en Villa Traful. Buenos Aires: Edición del autor, 2009.

GARCÍA, A.; VALVERDE, S. Políticas estatales y procesos de etnogénesis en el caso de poblaciones Mapuche de Villa La Angostura, provincia de Neuquén, Argentina. Cuadernos de Antropología Social, Buenos Aires, n. 25, p. 111-132, 2007.

GARCÍA, A., TRENTINI, F.; BERSTEN, L. Villa Traful, un pueblo patagónico de frontera. In: VALVERDE, S.; GARCÍA, A.; BERSTEN, L. (Org.). Relatos Patagónicos: historias familiares en la construcción del espacio social en Villa Traful. Córdoba: Ferreyra Editor, 2008.

GHIOLDI, G. (Org.). Historias de las familias mapuche Lof Paichil Antriao y Lof Quintriqueo, Mapuche de la margen norte del lago Nahuel Huapi. Neuquén: Archivos del Sur, Biblioteca Popular Osvaldo Bayer, Ferreyra editor, p. 35-51, 2010.

GIMÉNEZ, G. Cultura, identidad y memoria: Materiales para una sociología de los procesos culturales en las franjas fronterizas., Tijuana: Frontera Norte, 2008.

HERRÁN, C. Antropología Social en la Argentina. Apuntes y perspectivas. Cuadernos de Antropología Social, Buenos Aires, n. 10, p. 108-114, 1990.

HARRIS, M. El desarrollo de la teoría antropológica: historia de las teorías de la cultura. México D. F.: Siglo XXI, 1994.

INSTITUTO NACIONAL DE ESTADÍSTICAS Y CENSOS (INDEC). Censo Nacional de Población, Hogares y Viviendas 2001. Argentina, 2001. Disponible en: $<$ https://www.indec.gov.ar/micro_sitios/webcenso/>. Acceso en: 28 de may. 2018.

Censo Nacional de Población, Hogares y Viviendas 2010, Censo del Bicentenario. Resultados definitivos, Serie B No 2. Argentina, 2012. 
ITURRALDE, D. Los pueblos indios como nuevos sujetos sociales en los Estados latinoamericanos. Nueva Antropología, Ciudad de México, v. 11, n. 39, p. 27-40, 1991.

JORNADAS NACIONALES DE EDUCACIÓN. 2003-2013: La década ganada. Presidencia de la Nación, 2013.

JULIANO, M. D. Los Mapuches, la más larga resistencia. Anuario del Instituto de Estudios Histórico Sociales (IEHS), Buenos Aires, n. 11, p. 303-327, 1996.

MASES, E. Estado y cuestión indígena: el destino final de los indios sometidos en el sur del territorio (1878-1910). Buenos Aires: Prometeo Libros, 2010.

MÉNDEZ, L. El Estigma de origen. Chilenos e indígenas en el gran lago 1880-1935. In: GHIOLDI, G. (Org.). Historia de las familias Paichil Antriao y Quintriqueo de la Costa Norte del lago Nahuel Huapi. Neuquén: Archivos del Sur - Biblioteca Popular Osvaldo Bayer, 2009.

Circuitos económicos en el Gran Lago. La región del Nahuel Huapi entre 1880 y 1930. In: BANDIERI, S.; BLANCO, G. ; VARELA, G. (Org.). Hecho en Patagonia: la historia en perspectiva regional. Neuquén: Ediciones Centro de Estudios Históricos Regionales, Universidad del Comahue, 2006.

MATO, D. No "estudiar al subalterno", sino estudiar con grupos "subalternos" o, al menos, estudiar articulaciones hegemónicas de poder. Desafíos, Bogotá, v. 26, n. 1, p. 237-264, 2014. Disponible en: 〈http://www.redalyc.org/articulo.oa?id=359633175008>. Acceso en: 10 mar. 2015.

NAVARRO FLORIA, P. El proceso de construcción social de la región del Nahuel Huapi en la práctica simbólica y material de Exequiel Bustillo (1934-1944). Pilquen, Rio Negro, v. 10, n. 1, 2008.

PERAZZI, P. Comunidades científicas: la antropología en Buenos Aires, 1935-1975. Tesis Doctoral inédita. Buenos Aires: Facultad de Filosofía y Letras, Universidad de Buenos Aires, 2009.

PETZ, I. Movimientos Sociales y Estatalidad: de la desocupación a la construcción política: el caso de la Unión de Trabajadores Desocupados de General Mosconi en el Norte de Salta, Argentina. Tesis doctoral. Buenos Aires: Facultad de Filosofía y Letras de la Universidad de Buenos Aires, 2010.

Extensión universitaria: tendencias actuales y desafíos pendientes. Redes de

Extensión, Buenos Aires, n. 1, p. 1-5, 2015. Disponible en: 
〈http://revistascientificas.filo.uba.ar/index.php/redes/article/view/1461/1401>. Acesso em: 29 mayo 2018.

PETZ, I. et al. Sobre la construcción del derecho a la Universidad en la Argentina de comienzos del siglo XXI. In: LISCHETTI, M.; PETZ, I.; CUEVA, D. (Org.). Las transformaciones de las universidades latinoamericanas en el marco de las políticas regionales de la última década. Buenos Aires: Ediciones de la Facultad de Filosofia y Letras de la Universidad de Buenos Aires, 2016. p. 199-260.

PROGRAMA DE DERECHOS INDÍGENAS-FUNDACIÓN CHILE 21. Censo 2012. Pueblos Indígenas: primeros indicios. Disponible em: <http://derechosindigenaschile21.blogspot.com.ar/2013/04/se-inicia-difusion-de-los-res ultados.html >. Acesso en: 28 nov. 2015.

QUIJADA, M. Imaginando la homogeneidad: la alquimia de la tierra. In: BERNARD, C.; QUIJADA, M.; SCHNEIDER, A. Homogeneidad y nación: con un estudio de caso: Argentina, siglos XIX y XX. Madrid: Consejo Superior de Investigaciones Científicas, Centro de Humanidades, Instituto de Historia, 2000. p. 179-218.

RADOVICH, J. C. Política Indígena y Movimientos Étnicos: el caso Mapuche. Cuadernos de Antropología, Buenos Aires, n. 4, p. 47-65, 1992.

Identidad y conflicto en territorio mapuche: el caso Pulmarí. Ponencia presentada en el 50. ${ }^{\circ}$ Congreso Internacional de Americanistas, Varsovia: Mimeo, 2000.

Impacto social de grandes aprovechamientos hidroenergéticos sobre comunidades rurales de Norpatagonia. Tesis doctoral. Buenos Aires: Facultad de Filosofía y Letras, Universidad de Buenos Aires, 2003.

Los pueblos originarios de la Argentina. Situación Actual. In: BOVISIO, M.; RADOVICH, J. C. (Org.). Arte Indígena en tiempos del Bicentenario. Buenos Aires: Secretaría de Cultura de la Presidencia de la Nación, 2011. p. 75-99.

Política indígena y movimientos etnopolíticos en la Argentina Contemporánea. Una aproximación desde la Antropología Social. Antropologías del Sur, Santiago, v. 1, n. 1, p. 133-145, 2014.

RADOVICH, J. C.; BALAZOTE, A. El pueblo Mapuche contra la discriminación y el etnocidio. In: GHIOLDI, G. (Org.). Historia de las familias Mapuche Lof Paichil Antriao y Lof Quintriqueo: Mapuche de la margen norte del lago Nahuel Huapi. Neuquén: Archivos del Sur, Biblioteca Popular Osvaldo Bayer, Ferreyra editor, 2009. p. $35-59$. 
RAMOS, A. R. Indigenismo, un orientalismo Americano. I Encuentro de Antropólogos Brasileros y Mexicanos. México: 7- 9 set. 2011.

RAMOS, M. et al. La antropología: algunos conceptos, ramas y escuelas. In: BALAZOTE, A; RAMOS, M.; VALVERDE, S. (Org.). La antropología y el estudio de la cultura. Buenos Aires: Biblos, 2006. p. 19-38.

REPETTO, F. Políticas Sociales: una mirada político-institucional a sus reformas, desafíos e impactos. In: ACUÑA, C. (Org.). El Estado en acción. Siglo XXI, Buenos Aires, 2014. p. 19-69.

RATIER, H. La antropología social argentina: su desarrollo. Publicar en Antropología y Ciencias Sociales, Buenos Aires, n. 9, p. 17-47, 2010.

ROCKWELL, E. La experiencia etnográfica: historia y cultura en los procesos educativos. Buenos Aires: Paidós, 2009.

ROTMAN, M.; BALAZOTE, A. Marcas en la antropología argentina: el enfoque "fenomenológico", una perspectiva teórico-metodológica hegemónica en la historia de la disciplina. Antropologías del Sur, Santiago, v. 3, n. 6, p. 29-46, 2016. Disponible en: <http://revistas.academia.cl/index.php/ads/article/view/799>. Acceso en 31 mayo 2018.

RUGGIERO, L. et al. El "Programa Nacional Mapa Educativo" como medio de articulación y visibilización del trabajo con pueblos originarios. Redes de Extensión, Buenos Aires, n. 2, p. 71-84, 2016.

SERBIN, A. Las organizaciones indígenas en la Argentina. América Indígena, Ciudad de México, v. 41, n. 3, p, 407-433, 1981.

TAMAGNO, L. Modelo agrícola, pueblos indígenas y pequeños productores. In: CARRASCO, A.; SÁNCHEZ, N.; TAMAGNO, L. (Org.). Modelo agrícola e impacto socio-ambiental en la Argentina: monocultivo y agronegocios. Argentina: Universidad Nacional de La Plata, Asociación de Universidades del Grupo Montevideo-Comité de Medio Ambiente, 2012. p. 45-83.

TOZZINI, A. "Descendemos de Juan Ñancucheo" Discusiones entre vinculaciones "reales" y plausibles. In: III Jornadas de Historia de la Patagonia. Bariloche: Universidad Nacional del Comahue, 2008.

TRINCHERO, H. Compromiso y distanciamiento: configuraciones de la crítica etnográfica contemporánea. Runa, Buenos Aires, v. 21, n. 1, p. 317-333, 1994. Disponible en: 〈http://revistascientificas.filo.uba.ar/index.php/runa/article/view/1404>. Acceso en 31 mayo 2018. 
Los Dominios del Demonio. Buenos Aires: EUDEBA, 2000.

Aromas de lo exótico (retorno del objeto) para una crítica del objeto antropológico y sus modos de reproducción. Buenos Aires: SB, 2007.

Las masacres del olvido: Napalpí y Rincón Bomba en la genealogía del genocidio y el racismo de estado en la Argentina. Revista Runa, v. 30, n. 1, p. 45-60, 2009.

TRINCHERO, H.; VALVERDE, S. De la "guerra con el indio" a los pueblos originarios como sujetos sociales y políticos: del Centenario al Bicentenario argentino. In: TRINCHERO, H.; CAMPOS MUÑOZ, L.; VALVERDE, S. (Org.). Pueblos indígenas, Estados nacionales y fronteras: tensiones y paradojas de los procesos de transición contemporáneos en América Latina (Tomo 1). Buenos Aires: Editorial de la Facultad de Filosofía y Letras de la Universidad de Buenos Aires, Universidad Academia Humanismo Cristiano, Consejo Latinoamericano de Ciencias Sociales (CLACSO), 2014. p. 175-222.

VALVERDE, S. De la invisibilización a la construcción como sujetos sociales: el pueblo indígena Mapuche y sus movimientos en Patagonia Argentina. Anuário Antropológico, 2013, n. 1, p. 139-166, 2013.

VALVERDE, S., GARCÍA, A.; BERSTEN, L. Relatos Patagónicos: historias familiares en la construcción del espacio social en Villa Traful. Córdoba: Ferreyra Editor, 2008.

VALVERDE, S. et al. Volver al territorio: memorias mapuches en el Parque Nacional Nahuel Huapi. Buenos Aires: Editorial de la Facultad de Filosofía y Letras, Universidad de Buenos Aires, 2013.

\section{Fuentes}

Ministerio de Educación Anuario Estadístico. Años 2008-2013. Secretaría de Políticas Universitarias, 2013. . Informe de Gestión Secretaría de Políticas Universitarias, 2014. Informe de Gestión Secretaría de Políticas Universitarias, 2015.

Ministerio de Ciencia, Tecnología e Innovación Productiva (2013). Indicadores de ciencia y tecnología. Argentina 2011. Disponible en: http://indicadorescti.mincyt.gob.ar/documentos/indicadores_2011.pdf (acceso: 29 de 
mayo de 2018).

"la angosturadigital" (2011). 27/12/2011, "Ocupan tierras de Parques Nacionales". En:http://laangosturadigital.com.ar/v3.1/home/interna.php?id not=25605\&ori=web .

Recebido em: 31/05/2018 * Aprovado em: 01/10/2018 * Publicado em: 29/12/2018 